\title{
Receptive-Field Plasticity in the Adult Auditory Cortex Induced by Hebbian Covariance
}

\author{
Scott J. Cruikshank and Norman M. Weinberger \\ Center for the Neurobiology of Learning and Memory, and the Department of Psychobiology, University of California, \\ Irvine, California 92717
}

The goal of this experiment was to evaluate the role of cellular interactions postulated by the Hebbian, or covariance, hypothesis in the induction of receptive-field (RF) plasticity in the adult auditory cortex (ACX). This was accomplished by determining whether a "covariance treatment" (see below) was sufficient to induce RF plasticity without behavioral experiences that normally induce such plasticity. During the covariance treatment (conducted in urethane-anesthetized adult guinea pigs), one tone was paired with excitatory juxtacellular current, applied to a single postsynaptic cell in the primary ACx. Excitatory current increased postsynaptic discharge, thereby increasing covariance between activity of the postsynaptic cell and its afferents that were activated by the tone. In alternation, within the same cell a second, different tone was paired with inhibitory juxtacellular current, decreasing covariance between the postsynaptic cell and afferents activated by the second tone. After treatment, responses to tones associated with increased covariance strengthened significantly relative to tones associated with decreased covariance, as predicted by the Hebbian hypothesis. This occurred in 7 of 22 (32\%) cells undergoing 120 pairing trials, but in only 4 of $38(11 \%)$ cells undergoing 60 trials. Fewer than $5 \%$ of cells showed significant effects opposite those predicted by the hypothesis. Significant plasticity lasted $\geq 15$ min. Probability of plasticity was significantly higher when the cortical electroencephalogram was nonsynchronized during treatment ( $5 / 9$ cells) than when synchronized ( $2 / 13$ cells). These findings support the role of presynaptic-postsynaptic covariance processes in the induction of adult neocortical RF plasticity and suggest that factors associated with cortical state "gate" such plasticity.

Key words: neocortex; cortical plasticity; adult plasticity; learning; EEG; microstimulation
A major challenge facing neuroscience is understanding how experience alters the functional circuitry of the mammalian neocortex and, consequently, modifies its processing of information. Contrary to traditional belief, it is becoming established now that controlled sensory experience, such as partial sensory deafferentation or learning, can change information processing in the adult neocortex. In the primary sensory neocortex, these changes have been measured as specific alterations in receptive fields (RFs) of individual neurons and distributions of RFs across cortical maps (for review, see Kaas, 1991; Gilbert, 1993; Merzenich and Jenkins, 1993; Weinberger, 1995). For example, learning produces modifications of RFs in the adult auditory cortex (ACX), characterized by increased cellular responses to tone frequencies that signal behaviorally important events (food or shock) and decreased responses to other frequencies (for review, see Weinberger, 1993).

The purpose of this experiment was to investigate the induction of RF plasticity in the adult $\mathrm{ACX}$, focusing on a modified form of the Hebbian hypothesis (Hebb, 1949), sometimes called the covariance hypothesis (for review, see Sejnowski and Tesauro, 1989; Fregnac and Shulz, 1994). This hypothesis relates induction of plasticity to the covariance between activity of a postsynaptic cell and its presynaptic afferents. Specifically, it predicts the following:

Received Aug. 7, 1995; revised Oct. 10, 1995; accepted Oct. 16, 1995.

This work was supported by National Institutes of Health/NIDCD research Grants DC02346-03 (N.M.W.) and MH10432-03 (S.C.). We thank Dr. Raju Metherate for technical advice, and Andy Son, '1hu Huynh, and 'lerrence Bjordaht for their help with surgery and data processing.

Correspondence should be addressed to N. M. Weinberger, Center for the Neurobiology of Learning and Memory, Bonney Center, University of California, Irvine, Irvine, CA 92717.

Copyright $\odot 1996$ Society for Neuroscience $0270-6474 / 96 / 160861-15 \$ 05.00 / 0$
(1) repeated pairing of afferent activity with increased postsynaptic activity (increased covariance) will strengthen the functional synaptic strength between the active afferents and the postsynaptic cell; and (2) repeated pairing of afferent activity with decreased postsynaptic activity (decreased covariance) will weaken the functional synaptic strength between the active afferents and the postsynaptic cell.

The Hebbian hypothesis has received much attention regarding neocortical RF plasticity because of its adaptability for neural models (Bienenstock et al., 1982; Clothiaux et al., 1991; Ahissar and Ahissar, 1994), the fact that some forms of plasticity in other systems follow Hebbian rules of induction (Kelso et al., 1986; Malinow et al., 1986; Sastry et al., 1986; Wigstrom et al., 1986; Dan and Poo, 1992; Lin and Glanzman, 1994), and indirect evidence from results of neocortical plasticity experiments (Rauschecker and Singer, 1981; Weinberger et al., 1990; Merzenich and Sameshima, 1993; Diamond et al., 1994).

Despite indirect support, there have been few direct tests of the involvement of Hebbian processes in experience-induced neocortical plasticity. A powerful way to demonstrate such involvement is to show that increases or decreases in presynaptic-postsynaptic covariance alone (as stated above) are sufficient to induce plasticity in the absence of normal behavioral experience. This strategy, pioneered by Carew et al. (1984) in Aplysia, recently has been applied by Fregnac et al. (1992) and Shulz and Fregnac (1992) to support the Hebbian hypothesis in orientation and ocular dominance plasticity in the visual cortex-plasticity that normally occurs after selective sensory experience during development (Wiesel and Hubel, 1963; Blakemore and Cooper, 1970; Hirsch and Spinelli, 1970). 
Figure 1. Experimental design. The temporal position of each experimental period for experiment 1 is shown; treatment is depicted at the bottom. Onsets and offsets of paired current and tones are simultaneous (100 msec each). Asterisk indicates temporal position of second treatment block in experiment 2; it was identical to the first (60 pairings, $10 \mathrm{~min} \mathrm{du}-$ ration) and was delivered after the immediate post (Immed Post). Subsequently, additional post measurements (15 min Post, 30 min Post) were obtained.

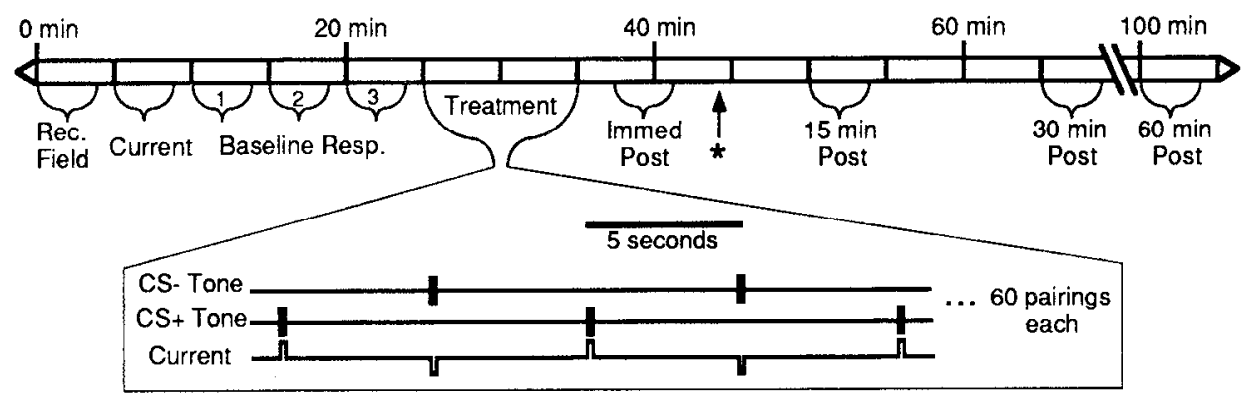

Using a similar strategy, we asked whether a treatment consisting of a period of altered presynaptic-postsynaptic covariance is sufficicnt for inducing RF plasticity in adult auditory cortical neurons in a manner predicted by the Hebbian hypothesis and consistent with findings from adult learning. We also asked whether other factors, such as cortical state, influenced the extent to which covariance treatments were effective at inducing plasticity.

\section{MATERIALS AND METHODS}

Summary of the design. For each auditory cortical cell recorded in this study (referred to as postsynaptic cells), two acoustic stimuli of differing frequency were presented as a method of activating two different populations of presynaptic afferents. After determination of baseline postsynaptic responses to these stimuli, a covariance treatment was imposed. During that treatment, one of the acoustic stimuli was paired repeatedly with excitatory postsynaptic current (see below for juxtacellular recording and stimulation) to increase the covariance between the activated afferents and the postsynaptic cell. The second acoustic presynaptic stimulus was paired with inhibitory postsynaptic current to decrease presynapticpostsynaptic covariance. After pairing, the subsequent effects on functional synaptic strength were examined and compared with the predictions of the Hebbian hypothesis.

Subjects and surgical preparation. Adult male IIartley guinea pigs $(n=$ $24,350-550 \mathrm{gm}$ ) were anesthetized with urethane (ethyl carbamate, 1.45 $\mathrm{gm} / \mathrm{kg}$, i.p.) and supplemented as needed $(0.3 \mathrm{gm} / \mathrm{kg})$ to maintain areflexia to hind limb stimulation. Electroencephalogram (EEG), heart rate, respiration, and core body temperature were monitored continuously. The EEG was recorded from stainless steel screws or small silver balls on the surface of the contralateral cortex, $\sim 1 \mathrm{~mm}$ posterior to the bregma and $1 \mathrm{~mm}$ lateral from the midline (single-ended, bandpass 1-100 $\mathrm{Hz}, 1000 \times$ amplification). A heating pad was used to maintain the body temperature at $37^{\circ} \mathrm{C}$. After the initial incision and resection of the scalp and periosteum, stainless steel screws.were threaded into the calvaria to anchor an acrylic pedestal containing threaded metal tubes. These were bolted to a frame attached to the stereotaxic apparatus to secure the skull without ear bars. An opening was made in the skull over the temporal cortex, and the $\mathrm{ACx}$ was located by position, vascular landmarks, and click-evoked field potentials. Small holes were cut in the dura mater to allow insertion of a recording-stimulating microelectrode into the $\mathrm{ACx}$.

Juxtacellular recording and stimulation. The microelectrode (glass $\mathrm{mi}-$ cropipette, $150 \mathrm{mM} \mathrm{KCl}$, tip diameter $0.5-1.5 \mu \mathrm{m}$, resistance 3-25 $\mathrm{M} \Omega$ ) was advanced perpendicular to the cortical surface by a stepping microdrive. At a depth of $400 \mu \mathrm{m}$, the penetration was halted temporarily and the cortex was covered with warmed agar ( $4 \%$ in saline) to prevent pulsation. In most cases, cisternal puncture and tracheal cannulation also were used to minimize cortical movement. After allowing the electrode to settle for $10 \mathrm{~min}$, the penetration was resumed $(\leq 1 \mu \mathrm{m} / \mathrm{sec})$ and the search for a single cortical neuron commenced. During this search, acoustic stimuli were presented while physiological activity (DC $-6 \mathrm{kHz}$, $0.3-6 \mathrm{kHz}$ activity, $100 \times$ amplification) and electrode resistance were monitored. Elcctrode resistance gencrally increased just beforc, or coincident with, the physiological detection of a neuron, indicating that the electrode was approaching the neuron (see Results).

After detection, the electrode was carefully advanced further until a juxtacellular configuration could be achieved, in which the tip of the microelectrode was situated close enough to the recorded soma that its action potentials were recorded as positive polarity waveforms with amplitudes of $3 \mathrm{mV}$ or larger. In this configuration, the microelectrode also could be used to control the activity of the recorded postsynaptic neuron with low levels of current ( $\leq 15 \mathrm{nA}, 100 \mathrm{msec})$ as described previously (Bienenstock et al., 1983; Fregnac et al., 1988; Andrew and Fagan, 1990). Positive current at the tip could excite the neuron locally into firing action potentials, and negative current at the tip could inhibit it from firing (see Results). A bridge circuit allowed uninterrupted recording during current pulses.

Procedure. The protocol after juxtacellular isolation is summarized in Figure 1. First, the RF (or Rec. Field) of the isolated auditory cortical neuron was characterized. Tones were delivered to the ear contralateral to the recording locus via a calibrated acoustic delivery system (100 $\mathrm{msec}$ pure tones, $0.1-30 \mathrm{kIIz}, 0-90 \mathrm{~dB}$, risc-fall timc $5 \mathrm{mscc}, 1$ tonc/sec) using a small speaker fixed in place at the opening of the external auditory meatus (near field) (Suga and Manabe, 1982). Threshold tuning curve, best frequency (BF), evoked spike rates for the different tone frequencies within the RF, and bandwidth were determined for all cells in the study. Bandwidth was obtained at the intensity to be used for subsequent treatment (see below) and was calculated as the distance between the low and high frequencies eliciting responses that were $50 \%$ of the maximum response for that intensity. Two acoustic stimuli (the $\mathrm{CS}^{+}$and $\mathrm{CS}^{-}$) were chosen from this RF characterization for use in the subsequent experimental periods. They were different frequencies (one lower than and the other higher than the BF) delivered at the same intensity $(\sim 20 \mathrm{~dB}$ above the BF threshold; see also Results), and both elicited excitatory responses. Next, the response to positive juxtacellular current was charactcrized according to thrcshold, spike rate, and latency. A positive current value $\sim 25 \%$ above the threshold for eliciting spikes was chosen for subsequent pairing (mean threshold, $8.5 \mathrm{nA}$ ). Approximately matching negative current values also were chosen (see Results).

This was followed by a 15 min baseline period, during which the responses of the postsynaptic cell to 60 alternating presentations of the $\mathrm{CS}^{+}$and $\mathrm{CS}^{-}$tones were recorded (separated into three blocks, with 20 of each tone per block). Next, the "covariance" pairing treatment was administered (Fig. 1, bottom). The $\mathrm{CS}^{+}$and $\mathrm{CS}^{-}$tones were delivered 60 times each in alternation $(0.1 \mathrm{~Hz})$. The response of the postsynaptic cell was increased for the $\mathrm{CS}^{+}$by applying simultaneous positive juxtacellular current. The response was reduced for the $\mathrm{CS}^{-}$by applying negative current. Immediately after the treatment, the responses to the tones alone were redetermined [ 20 trials each without any current (Immed Post in Fig. 1)]. For onc set of ncurons (cxpcriment $1, n=10$ ), post measurements were taken at 15 min intervals for up to $1 \mathrm{hr}$, with no additional treatment. In another set (experiment $2, n=28$ ), a second treatment block ( 60 trials) was implemented before additional post measurements to test whether a greater amount of exposure to the pairing treatment would have a greater effect.

An additional difference between experiments 1 and 2 was a slight variation in the way that the Baseline and Post periods (but not the Rec. Field, Current, or Treatment periods) were conducted. In experiment 1, 11 different tone frequencies were presented during the baseline and post periods. These included the $\mathrm{CS}^{+}$and $\mathrm{CS}^{-}$frequencies and nine others. The additional frequencies were included to examine possible gradients of effects on the overall tuning of the postsynaptic cell that would not be detected simply by examining responses to the two paired frequencies. However, we did not detect any such gradients in experiment 1 , so in experiment 2 the protocol was simplified, and only the two paired frequencies were presented. The difference in number of frequencies presented during the baseline and post periods did not appear to have an effect, because the results of experiment 1 and the results after the first 60 trials of experiment 2 were almost identical (see Results).

Data analysis. The spike rate responses evoked by each presentation of the $\mathrm{CS}^{+}$and $\mathrm{CS}^{-}$were collected during the baseline, treatment, and post 
periods. These spike rates were averaged over the entire $100 \mathrm{msec}$ of tone duration (for all cells during all experimental periods) to "capture" the majority of evoked spikes while avoiding periods of inhibition that often followed offsct of the tonc. Using thesc spike rates, the relative response to the $\mathrm{CS}^{+}$versus the $\mathrm{CS}^{-}$was calculated for each trial (a trial is one sequential presentation of the $\mathrm{CS}^{+}$and $\mathrm{CS}^{-}$) as follows:

$$
\text { Index }=\frac{\left(\text { spike rate to } \mathrm{CS}^{+}\right)}{\left(\text {spike rate to } C \mathrm{~S}^{+}\right)+\left(\text {spike rate to } \mathrm{CS}^{-}\right)}
$$

This relative response will be referred to as either the " $\mathrm{CS}^{+}$versus $\mathrm{CS}^{-}$ index" or simply the "index." The potential values of the index range from 0.0 to 1.0. A value close to 1.0 indicates a strong preference for the $\mathrm{CS}^{+}$, a value close to 0.0 indicates a strong preference for the $\mathrm{CS}^{-}$, and a value close to 0.5 indicates approximately equal preferences for the $\mathrm{CS}^{+}$ and $\mathrm{CS}^{-}$.

ANOVA was used to examine the stability of the index scores across the three baseline blocks. Only neurons that were stable (indicated by $p$ $>0.05$ ) were used in subsequent analyses. After determining that the three baseline blocks were not significantly different from one another, they were collapsed into a single block for comparison with the treatment and post periods. Unpaired $t$ tests were used to examine differences between the baseline period and other periods (significant difference indicated by $p<0.05$ ).

\section{RESULTS}

\section{Choice of CS tones, baseline, and treatment}

Choice of the $\mathrm{CS}^{+}$and $\mathrm{CS}^{-}$tones

On average, the acoustic intensity chosen for the $\mathrm{CS}^{+}$and $\mathrm{CS}^{-}$ tones was $\sim 20 \mathrm{~dB}$ above the threshold of the cell; mean threshold (at the BF) was $45 \pm 3 \mathrm{~dB}$, and mean intensity used for the CS tones was $64+2 \mathrm{~dB}$. The mean frequency chosen as the $\mathrm{CS}^{+}$was $0.5 \pm 0.1$ octaves from the $\mathrm{BF}$, and the mean $\mathrm{CS}^{-}$was $0.3 \pm 0.1$ octaves from the BF. Because of the greater distance from the BF, the average baseline response to the $\mathrm{CS}^{+}$was weaker than the response to the $\mathrm{CS}^{-}(11 \pm 1$ vs $19 \pm 2$ spikes/sec, respectively). Comparison of the mean response with the BF tone $(27 \pm 4$ spikes/sec; presented at the same intensity as the CS tones) reveals that the baseline responses to both the $\mathrm{CS}^{+}$and $\mathrm{CS}^{-}$were moderate (41-70\% of those elicited by the BF stimulus), allowing for potential increases and decreases that might occur because of the treatment.

\section{Baseline and treatment periods}

During the baseline period, the $\mathrm{CS}^{+}$versus $\mathrm{CS}^{-}$index values were stable for 38 postsynaptic neurons recorded from 24 animals (ANOVA; $p>0.05$ ). During the treatment period, the responses of all 38 postsynaptic neurons were controlled so that each had a significant increase in the $\mathrm{CS}^{+}$versus $\mathrm{CS}^{-}$index $(p<0.05, t$ test, treatment period vs baseline). Group data in Figure 2 show that application of positive postsynaptic current produced more than a threefold increase in the mean response to the $\mathrm{CS}^{+}$(Fig. 2A), and application of negative current produced an almost fourfold decrease to the $\mathrm{CS}^{-}$(Fig. $2 B$ ). Because of these changes, the mean $\mathrm{CS}^{+}$versus $\mathrm{CS}^{-}$index more than doubled (Fig. $2 \mathrm{C}$ ).

\section{Local nature of the juxtacellular current}

The strong increases and decreases in postsynaptic responses imposed during treatment (see above) are assumed to indicate corresponding increases and decreases in covariance (between the postsynaptic cell and the presynaptic afferents activated by the $\mathrm{CS}^{+}$and $\mathrm{CS}^{-}$, respectively). This, of course, requires that the effects of the treatment current on neural discharge are highly local and confined primarily to the postsynaptic cell. There are two major indications that this was the case in these experiments. The first indication is simply the low current levels used. The
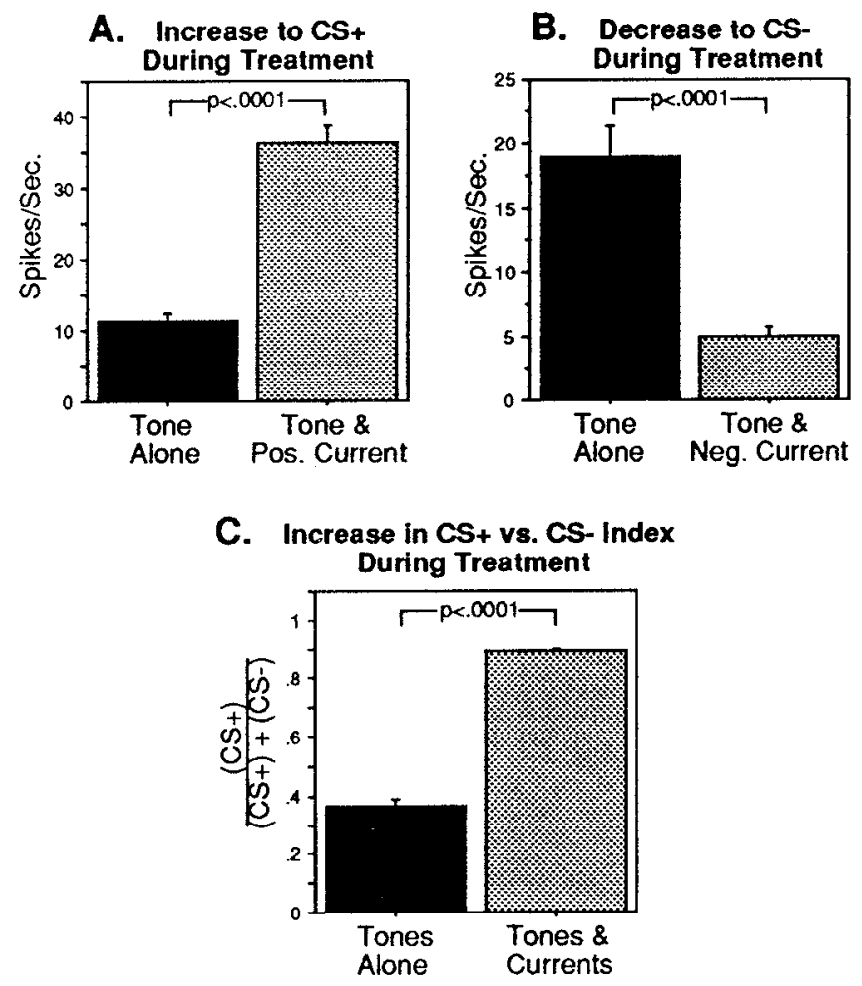

Figure 2. Control of responses during treatment. The group responses ( $n$ $=38$ ) to tones alone (baseline period, black bars) are compared with the responses to the same tones in the presence of postsynaptic current (treatment period, gray bars). Group data are presented for the $\mathrm{CS}^{+}(A)$, the $\mathrm{CS}^{-}(B)$, and the $\mathrm{CS}^{+}$versus $\mathrm{CS}^{-}$index $(C)$. The two treatment periods are averaged for the cells from experiment 2. Probabilities shown are from paired $t$ tests. Note that both the positive and negative currents controlled responses to the $\mathrm{CS}^{+}$and $\mathrm{CS}^{-}$tones, respectively.

mean positive current applied was $10.6 \pm 0.7 \mathrm{nA}$, and the mean negative current was $-9.7 \pm 0.6 \mathrm{nA}$ (range $0.5-15.0 \mathrm{nA}$ ). These values are three to five orders of magnitude below current levels typically used with extracellular stimulation (for review, see Ranck, 1975) (Gerken, 1984; Salzman et al., 1990; Cruikshank et al., 1992; Maldonado and Gerstein, 1992; Recanzone et al., 1992; Kitzes and Doherty, 1994), suggesting minimal effective spread. More specifically, it is estimated that current of at least $300 \mathrm{nA}$ is required to excite neurons located $50 \mu \mathrm{m}$ from a stimulating electrode (Ranck, 1975). This level is $\sim 20$ times greater than the maximum current used in the present studies $(15 \mathrm{nA})$, indicating that the effective spread here is $<50 \mu \mathrm{m}$.

The second indication that the current effects were confined primarily to the postsynaptic cell emerged from the measured relationship between the effectiveness of current and the presumptive distance between the cell and the micropipette. A typical example is given in Figure 3. As the pipette was advanced, spike amplitudes (Fig. 3A) and electrode resistances (Fig. 3B) increased, while threshold current levels decreased systematically (Fig. 3C). Thus, the nearer the electrode tip to the cell (as indicated by recorded spike amplitudes and electrode resistances; see Fig. 3 legend), the more effective the current. Furthermore, there were some electrode positions (e.g., where the cell was detected initially; see legend) for which the cell was near enough to the electrode for large spikes to be recorded $(0.5-3.0 \mathrm{mV})$ but for which current was ineffective within the $15 \mathrm{nA}$ range used. Thus, the electrode tip had to be very close to the cell for current to be effective-closer than the recording range. This makes it 
A.

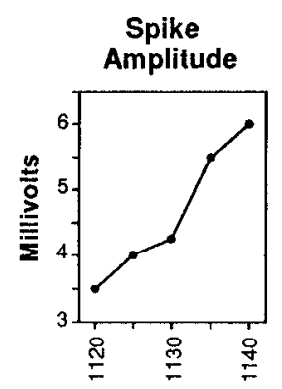

B.

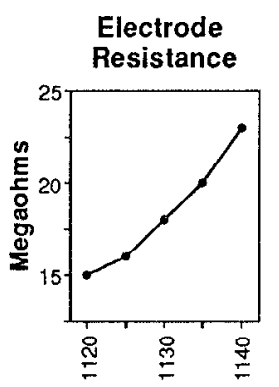

c.

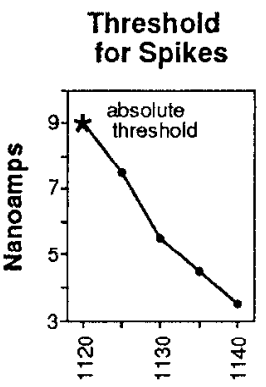

Electrode Position: Distance from cortical surface ( $\mu \mathrm{M})$

Figure 3. Effect of current depends on distance between cell and electrode. The relationships between electrode position and spike amplitude $(A)$, electrode resistance $(B)$, and threshold current levels necessary for cliciting spikes $(C)$ are shown. Recorded spikc amplitude and clcctrode resistance $\left(R_{\mathrm{e}}\right)$ are presumed to be inversely proportional to the distance between the cell and electrode tip. Spike amplitude is inversely related to distance, because the electric ficld caused by the discharge of a neuron decreases with distance (Lemon, 1984). $R_{\mathrm{e}}$ increases as a micropipette (of the kind used here, $0.5-1.5 \mu \mathrm{m}$ ) approaches a neuron, presumably because the tip of the pipette presses against the cell membrane (or associated tissues), blocking the flow of ionic current through the pipette (Hamill et al., 1981; Blanton et al., 1989). This cell, like nearly all cells included in this study, was detected first by the emergence and growth of extracellularly recorded spikes, as well as by an accompanying increase in $R_{\mathrm{e}}$. As the electrode was lowered from 1100 to $1115 \mu \mathrm{m}$ from the cortical surface, spike amplitude increased from noise levels to $3.0 \mathrm{mV}$, whereas $R_{\mathrm{e}}$ increased from an original value of 3.5 to $13 \mathrm{M} \Omega$ (data not shown). No amount of current within the $15 \mathrm{nA}$ limit of our system could elicit spikes from this cell while the electrode was above the first graphed point of 1120 $\mu \mathrm{m}$. At $1120 \mu \mathrm{m}$, the cell could be activated by $9 \mathrm{nA}$ (see asterisk in $C$ ); spike amplitude was $3.5 \mathrm{mV}(A)$, and $R_{\mathrm{c}}$ was $15 \mathrm{M} \Omega(B)$. As the electrode was stepped to $1140 \mu \mathrm{m}$, spike amplitude and $R_{\mathrm{e}}$ increased further, indicating that the electrode was encroaching further on the cell. At the same time, threshold current for spikes decreased $(C)$. The two measures indicating proximity of the electrode to the cell (spike amplitude and $R_{\mathrm{e}}$ ) correlated positively with each other $(r>0.97, p<0.01)$ and negatively with threshold current $(r<-0.94, p<0.02)$. As the electrode was advanced beyond $1140 \mu \mathrm{m}$, the neuron became injured and eventually was killed. No action potential waveforms from other neurons were recorded within several tens of microns of this cell.

improbable that the currents were effective on cells other than the recorded ccll, bccause they were outside the recording range. In the unlikely event that there were such effects, they would not be as strong as the effect on the recorded cell, because effectiveness of current diminished with distance (see above) and because the recorded cell was likely to be the nearest cell to the electrode tip (its electric field usually was the only field recorded by the electrode and was always the largest). In conclusion, the effects of the juxtacellular current appear to be highly localized to the postsynaptic cell. Thus, it can be reasonably assumed (keeping in mind the caveat that suprathreshold postsynaptic discharge, even with intracellular stimulation, can influence local cortical circuits) that the strong control over postsynaptic responses imposed during treatment (Fig. 2) indicates strong control over presynapticpostsynaptic covariance.

\section{Post-treatment main effects}

\section{Experiment 1}

Immediately after the covariance treatment in experiment $1(60$ trials, $\mathrm{CS}^{+}$and $\mathrm{CS}^{-}$paired with positive and negative current, respectively), only one neuron $(1 / 10,10 \%)$ showed a significant increase in the $\mathrm{CS}^{+}$versus $\mathrm{CS}^{-}$index compared with baseline. No

\section{A. Non-Significant Increase After 60 Treatment Trials}

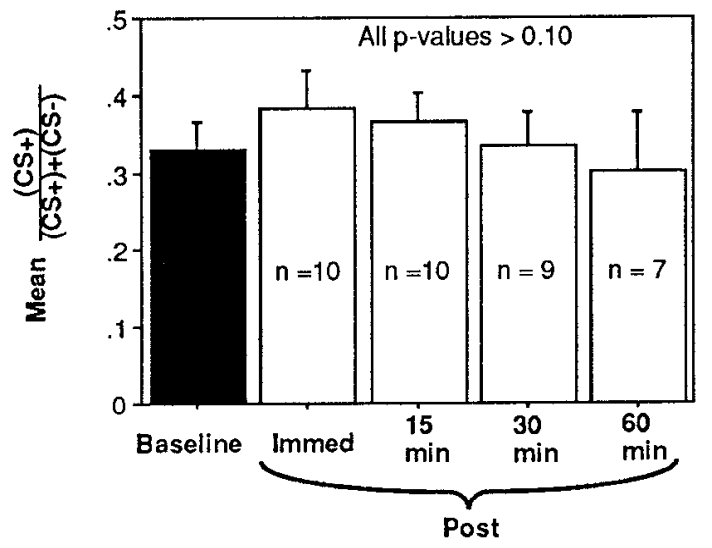

\section{B. Strength of imposed change during treatment correlates with post-treatment effects}

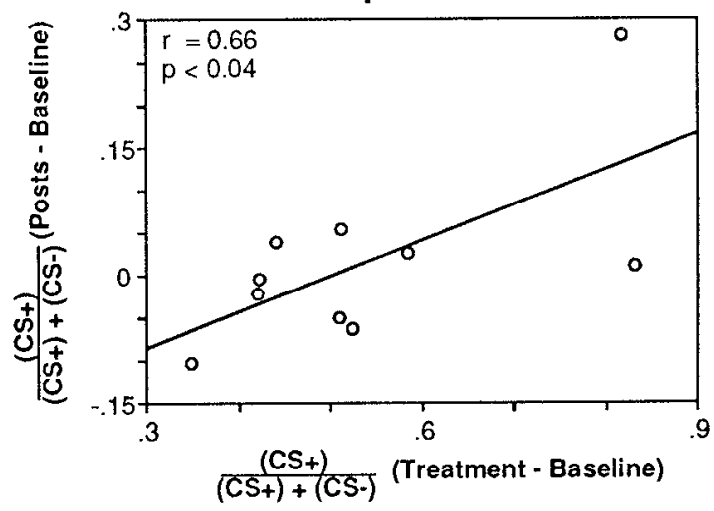

Figure 4. Experiment 1 post-treatment results. $A$, Mean group $\mathrm{CS}^{+}$ versus $\mathrm{CS}^{-}$index values for the baseline and each post-treatment period. Note the nonsignificant increase immediately after pairing that decayed to baseline levels within $30 \mathrm{~min}$. There were no significant differences between the baseline and any of the post periods $(p>0.10$, unpaired or paired $t$ tests). $B$, For each neuron in experiment $1(n=10)$, the postpairing change in the $\mathrm{CS}^{+}$versus $\mathrm{CS}^{-}$index ( $y$ axis; averaged across all four post-periods: Immed, $15 \mathrm{~min}, 30 \mathrm{~min}$, $60 \mathrm{~min}$ ) was plotted versus the change imposed during the treatment ( $x$ axis). Observe the significant correlation $(p<0.04)$, indicating that the largest post-treatment increases tended to come from neurons most strongly controlled during the treatment.

cells showed a significant decrease. Group data revealed a nonsignificant trend toward an increase in the index, which decayed back to baseline within 30 min (Fig. $4 A$ ).

Although these findings generally were in the direction predicted by the Hebbian hypothesis (i.e., increases in the index), they were very weak, suggesting that covariance manipulations might be insufficient to induce significant RF plasticity in this system (see also Cruikshank and Weinberger, 1993). However, there was a statistically significant correlation between the strength of the treatment and the magnitude of the post-treatment change (Fig. $4 B$ ), indicating that the overall postpairing plasticity might be enhanced if the strength of the covariance treatment could be increased. Despite this indication, we did not attempt to increase the mean strength of the treatment per pairing trial for several reasons. First, the control exerted during the treatment in experiment 1 already was quite strong, actually increasing the $\mathrm{CS}^{+}$ response above the response to the $\mathrm{BF}(7 \mathrm{spikes} / \mathrm{sec}$ for baseline $\mathrm{CS}^{+}, 34$ spikes/sec for treatment $\mathrm{CS}^{+}, 27$ spikes/sec for baseline 


\section{Table 1. Experiment 2 Post-treatment effects on the $\mathrm{CS}^{+}$vs $\mathrm{CS}^{-}$index}

\begin{tabular}{llll} 
& After first treatment & After second treatment & 15 min after treatment \\
\hline Significant increases on index ${ }^{a}$ & $3 / 28(10.7 \%)$ & $7 / 22(31.8 \%)$ & $7 / 20(35.0 \%)$ \\
Significant decreases on index ${ }^{b}$ & $1 / 28(3.6 \%)$ & $0 / 22(0.0 \%)$ & $1 / 20(5.0 \%)$ \\
Sign tests ${ }^{c}$ & $p=0.63$ & $p=0.02$ & $p=0.07$
\end{tabular}

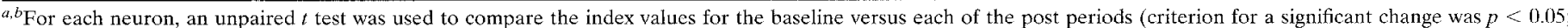
ratios of cells with significant increases and decreases are shown as a function of the total number recorded for each period).

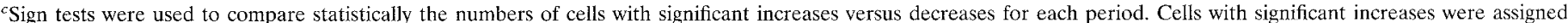

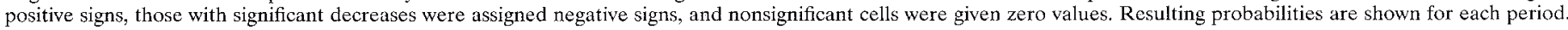

$\mathrm{BF})$ and decreasing the response by more than half for the $\mathrm{CS}^{-}$ (13 spikes/sec for baseline, 5 spikes/sec for treatment). Second, pilot experiments revealed that increasing current levels above the $\pm 15 \mathrm{nA}$ range used in experiment 1 caused reductions in recording integrity, e.g., blocking of the amplifier and pipette and, occasionally, injury discharges. Finally, increasing current levels could cause unwanted decreases in the specificity, possibly attributable to current spread (see above). Therefore, another strategy was used to increase the overall treatment strength: pairing trials were added, while keeping the imposed strength per trial approximately constant.

\section{Experiment 2}

In experiment $2(n=28)$, a second treatment block ( 60 additional pairing trials) was delivered immediately after the initial post measurement (see asterisk in Fig. 1). This second treatment then was followed by additional post measurements (immediate, 15 $\mathrm{min}$, and $30 \mathrm{~min}$ ). For 6 of 28 neurons, the recordings became unstable during, or immediately after, the second treatment (presumably because of mechanical instability that developed during the $15 \mathrm{~min}$ required for the second treatment and post measurement; Fig. 1). Consequently, no post measurements were completed after the second treatment for these neurons, leaving 22 neurons with two complete sets of treatment and immediate post data.

The first 60 pairings of experiment 2 produced results similar to those of experiment $1 ; 3$ of $28(11 \%)$ neurons had significant increases in the $\mathrm{CS}^{+}$versus $\mathrm{CS}^{-}$index immediatcly after the treatment, whereas only 1 cell had a significant decrease. However, there were more significant effects after the second block of 60 pairings; immediately after the second treatment block, 7 of 22 $(32 \%)$ neurons exhibited significant increases in the index, with no decreases (Table 1). Therefore, administering the additional 60 pairing trials significantly increased the probability of plasticity in the direction predicted by the Hebbian hypolhesis $(p<0.02$, sign test; Table 1).

The significant increases in the $\mathrm{CS}^{+}$versus $\mathrm{CS}^{-}$index values were caused by several types of changes. For example, some were caused by actual increases to the $\mathrm{CS}^{+}$(without decreases to the $\mathrm{CS}^{-}$), others were caused by decreases to the $\mathrm{CS}^{-}$(without increases to the $\mathrm{CS}^{+}$), and still others were caused by combinations of changes in both the $\mathrm{CS}^{\prime}$ and $\mathrm{CS}$ responses. Individual examples of each of these types of results are illustrated in Figures 5,6 , and 7, respectively. These examples also illustrate the range of patterns of development of the effects. For example, in Figure 7 there was a significant increase in the $\mathrm{CS}^{+}$versus $\mathrm{CS}^{-}$index immediately after the first treatment, whereas in Figure 6 no increase appeared until after the second treatment. The effect on the cell in Figure 5 is midway between those in Figures 6 and 7; it had a nonsignificant but detectable increase after the first treat- ment that became statistically significant only after the second treatment.

To examine systematically the development and maintenance of the plasticity, the $\mathrm{CS}^{+}$versus $\mathrm{CS}^{-}$index values for the seven significant neurons are plotted for each period in Figure 8 . The clearest pattern of development was that nearly all of these neurons (6/7) had an increase in the index after the second treatment (compared with the response immediately before that treatment) regardless of the effect of the first treatment. Stable recordings were maintained for 7 cells through $15 \mathrm{~min}$ and 4 cells through $30 \mathrm{~min}$. Significant plasticity was maintained for 6 of 7 cells at $15 \mathrm{~min}$ and for 2 of 4 cells at $30 \mathrm{~min}$.

Thus far, the findings of experiment 2 have concentrated on individual neurons that met a statistical criterion for significant change. However, we also examined the effects of the covariance treatment on the group as a whole, including neurons that did not attain statistical significance. Figure $9 A$ shows that the group results echo the previous individual neuron data for experiment 2 ; there was no significant group change after the first treatment and a significant increase after the second treatment that was maintained for at least $15 \mathrm{~min}$.

The changes in response to both the $\mathrm{CS}^{+}$and the $\mathrm{CS}^{-}$are presented for each neuron in Figure $9 B$. As in the previous analysis, there was no systematic change after the first treatment (13/28 favored the $C S^{+} ; p=0.85$, sign test), but there was a significant change in favor of the $\mathrm{CS}^{+}$compared with the $\mathrm{CS}^{-}$ immediately after the second treatment (18/22 favoring $\mathrm{CS}^{+} ; p<$ $0.01)$ that lasted $15 \mathrm{~min}\left(16 / 20\right.$ favoring $\left.\mathrm{CS}^{+} ; p<0.02\right)$. Notice that after the second treatment, 11 of the 15 nonsignificant effects were in favor of the CS . Figure $9 B$ also shows that the relative increases to the $\mathrm{CS}^{+}$were attributable primarily to decreases in response to the $\mathrm{CS}^{-}$and not to actual increases to the $\mathrm{CS}^{+}$. For example, immediately after the second treatment (Fig. 9B, middle), there are more decreases for the $\mathrm{CS}^{-}$(16/22 decreases, 6/22 increases) but equal numbers of increases and decreases for the $\mathrm{CS}^{+}(11 / 22$ decreases, $11 / 22$ increases $)$.

\section{Factors relating to plasticity (experiment 2)}

In summary, it was found that there was a population of neurons ( $32 \%$ of the sample) in the ACx for which a treatment, consisting of 120 covariance pairings, was sufficient to induce statistically significant RF plasticity in the direction predicted by the Hebbian hypothesis. Although this ratio of significant positive effects itself is statistically significant considering that there were no significant effects in the nonpredicted direction $(p<0.02$; Table 1$)$, it remains a minority of the sample. The critical question, therefore, is whether there are other factors that influence the degree to which the covariance treatment was effective at inducing plasticity. Next, we report data pertinent to three such factors. 


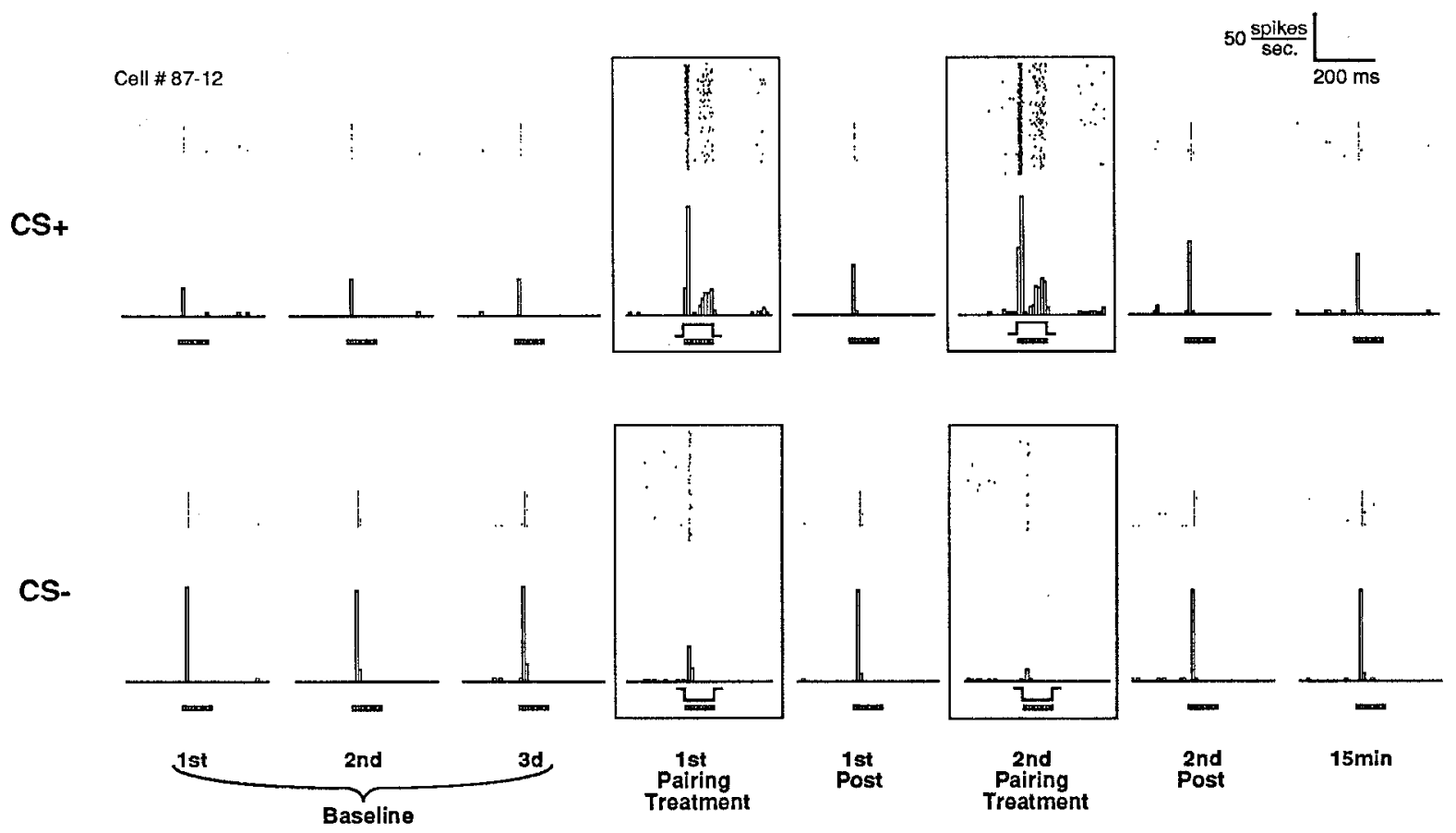

Figure 5. An increase in the $\mathrm{CS}^{+}$versus $\mathrm{CS}^{-}$index attributable to a $\mathrm{CS}^{+}$increase. Peristimulus time histograms (PSTs) and associated raster plots are presented for the $\mathrm{CS}^{+}$(top) and the $\mathrm{CS}^{-}$(bottom). Measurement periods are labeled along the bottom. The PSTs are divided into 10 msec bins along the $x$ axis. Response values are normalized to spikes/sec on the $y$ axis (calibration in top right). Each dot in a raster represents a spike. Successive trials for a given period are stacked in rows on one another. The rasters for the treatment periods have more rows, because they represent the responses to 60 trials rather than to 20 trials. Baseline, 1st Pairing Treatment, 1st Post: For this neuron, the $\mathrm{CS}^{+}$response was consistently weaker than the $\mathrm{CS}^{-}$for the baseline period, resulting in a low mean index value (baseline, $0.17 \pm 0.03$ ). There were no differences between the three blocks of index scores in the baseline $(p>0.9)$. During the first treatment, a significant increase in the $\mathrm{CS}^{+}$response and a significant decrease in the $\mathrm{CS}^{-}$response produced a significant increase in the index (first trcatment, $0.76 \pm 0.04 ; p<0.0001$ ). Immediatcly after the first treatment, there was a nonsignificant, but perceptible, increase in the $\mathrm{CS}^{+}$response compared with baseline and almost no change in the $\mathrm{CS}^{-}$, which resulted in a nonsignificant increase in the index (first post measurement, $0.28 \pm 0.05 ; p=0.08)$. 2nd Paining Treatment, 2nd Post, 15min: During the second treatment, even greater changes were imposed for both stimuli (index, $0.95 \pm 0.01 ; p<0.0001$ ). Immediately after the second treatment, the $\mathrm{CS}^{-}$response was approximately equal to the baseline, but the CS response increased significantly $(p<0.001)$. This resulted in a significant increase in the index (second post measurement, $0.42 \pm 0.04, p<0.0001)$. By $15 \mathrm{~min}$, the $\mathrm{CS}^{+}$response had begun to decline, but was still significantly larger than baseline $(p<0.03)$, as was the index $(0.33 \pm 0.05 ; p<0.02)$.

\section{Cortical state}

In urethane-anesthetized animals, the cortical EEG alternates between periods of synchrony and desynchrony, even while these animals are anesthetized deeply as indicated by areflexia (for general effects of urethane anesthesia, see Maggi and Meli, 1986). It is known that shifts in cortical EEG have profound influences on cortical processing of sensory inputs (Brugge and Merzenich, 1973; Livingstone and Hubel, 1981) (for review, see Steriade and McCarley, 1990). Moreover, the neuromodulators involved in EEG shifts (Buzsaki et al., 1988; Berridge and Foote, 1991; Metherate et al., 1992) (for review, see Steriade et al., 1993) also have been implicated in cortical plasticity (Kasamats11, 1985; Rear and Singer, 1986; Greuel et al., 1988; Rasmusson and Dykes, 1988; Metherate and Weinberger, 1989; Delacour et al., 1990; Juliano et al., 1991; Webster et al., 1991; Edeline et al., 1994). Therefore, the question posed here was whether the state of the cortex during treatment influences how a cell is affected by that treatment. To examine this possibility, the cortical EEGs during the treatment periods first were categorized as (1) desynchronized, (2) synchronized, or (3) transition (i.e., shifting between desynchronized and synchronized). EEG categorization was done blind. Figure $10 A$ gives representative EEG records. For statistical analysis, the desynchronized and transition groups were collapsed into one "nonsynchronized" group, because there were only two completely desynchronized cases. The plasticities ob- served for the two EEG categories then were compared. Figure $10 B$ shows that the probability of significant plasticity was greater if the cortical EEG was nonsynchronized during the pairing treatment than if it was synchronized; 5 of $9(56 \%)$ cells that underwent treatment when the EEG was nonsynchronized were affected, whereas only 2 of $13(15 \%)$ that underwent treatment when the EEG was synchronized were affected significantly $\left(\chi^{2}=\right.$ $3.96, p<0.05)$.

From the results presented thus far, the mechanism of the EEG influence is not clear. For example, one way that factors associated with EEG nonsynchrony might exert their effect on plasticity is by increasing directly the strength of the covariance changes during the treatment. However, this possibility was excluded; the mean changes in the index values imposed during treatment were nearly identical for the two EEG groups (synchronized, $0.50 \pm$ 0.04 ; nonsynchronized, $0.53 \pm 0.04 ; p>0.1, t$ test). Thus, the factors associated with cortical state must have exerted their influence on plasticity by some means other than by affecting directly the strength of covariance change during the treatments (see Discussion).

\section{Depth from the cortical surface}

Another factor that could contribute to whether a cell develops significant plasticity is laminar position. Difterent cortical laminae contain different cell types with different intrinsic physiological 


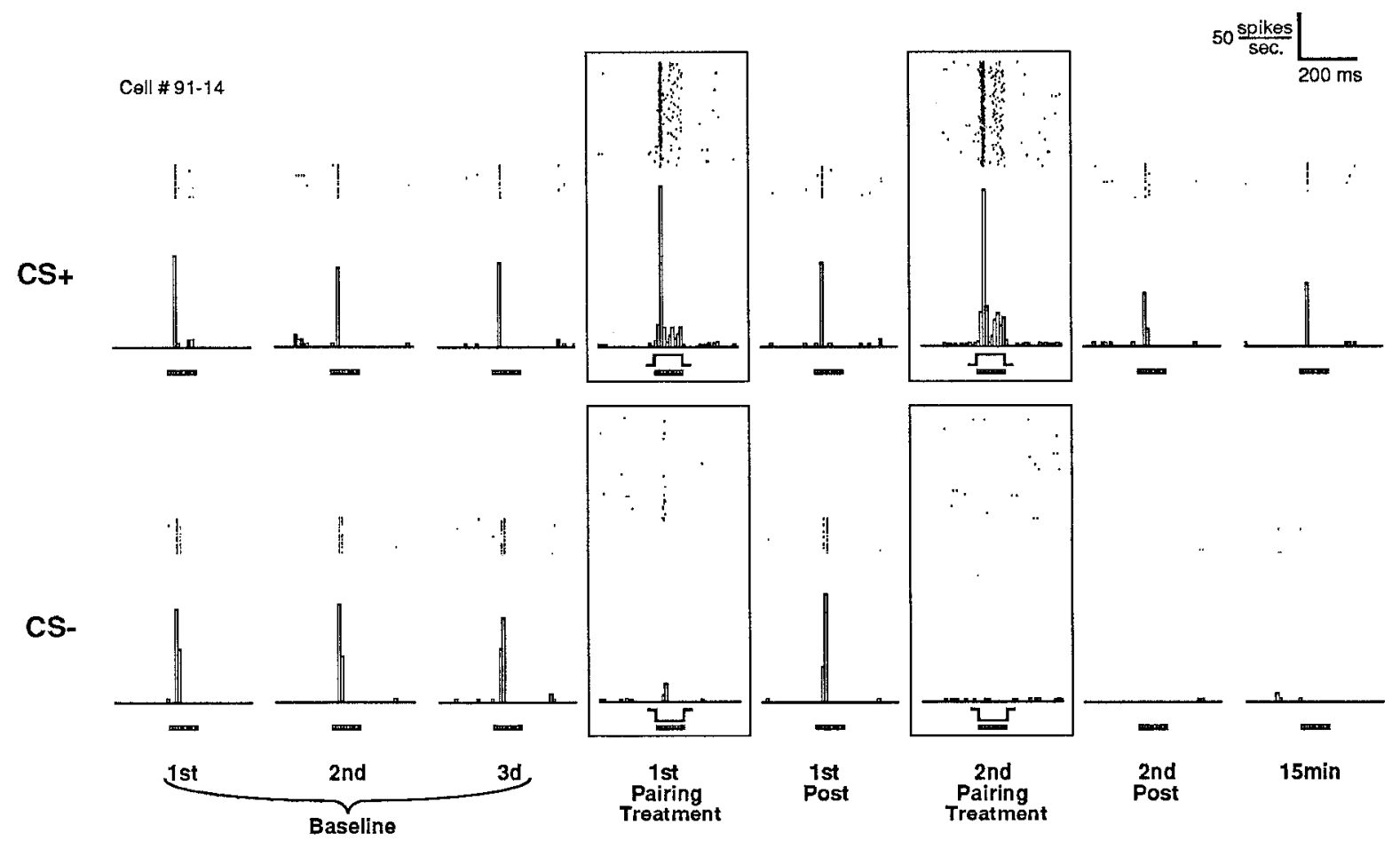

Figure 6. An increase in the $\mathrm{CS}^{+}$versus $\mathrm{CS}^{-}$index attributable to a $\mathrm{CS}^{-}$decrease. Baseline, 1 st Pairing Treatment, 1 st Post: The $\mathrm{CS}^{+}$response was slightly, but consistently, weaker than the $\mathrm{CS}^{-}$for the baseline period (index, $0.41 \pm 0.03$ ). There were no differences between the three blocks of index scores in the baseline $(p>0.7)$. During the first treatment, a significant increase in the $\mathrm{CS}^{+}$response and a significant decrease in the $\mathrm{CS}^{-}$response produced a significant increase in the index (first treatment, $0.92 \perp 0.02 ; p<0.0001$ ). Immediately after the first treatment, there was almost no change for either the $\mathrm{CS}^{+}$or $\mathrm{CS}^{-}$compared with baseline (first post index, $0.42 \pm 0.04 ; p>0.8$ ). 2nd Pairing Treatment, 2nd Post, 15min: During the second treatment, even greater changes in response to both CS stimuli were imposed; the response to the CS ${ }^{-}$was effectively eliminated (second treatment index, $0.99 \pm$ $0.01 ; p<0.0001)$. Immediately after the second treatment, the CS response was slightly reduced $(p>0.08)$, but the CS response was eliminated completely ( $\mathrm{CS}^{-}$for second post measurement, $\left.0.0 \pm 0.0 ; p<0.0001\right)$. This, of course, resulted in a significant increase in the index, which lasted for 15 min (both second and 15 min post measurements, $1.0 \pm 0.0 ; p<0.0001$ ). By 30 min, the $\mathrm{CS}^{-}$response returned so that the index fell to baseline levels (data not shown; see Fig. 8E). (See Fig. 5 for orientation and terminology.)

properties, receive different afferent projections, and have been shown to have different potential for other forms of synaptic plasticity (Jones, 1984; Tsumoto, 1990; Wallace et al., 1991; Connors, 1994; Diamond et al., 1994). Laminar position was estimated by comparing known depths of laminar boundaries with the depth of each recording from the cortical surface. Figure $11 \mathrm{~A}$ plots the distribution of cells with significant and nonsignificant plasticity as a function of laminar position (for experiment 2). It was found that the middle cortical depths (layer IV and upper layer V) had the highest proportion of cells with significant plasticity (6/12), whereas only one cell sampled from other locations was significant $(1 / 10)$. Statistical analysis revealed that it was unlikely that these differences in plasticity among layers were caused by chance $\left(\chi^{2}=\right.$ $4.02, p<0.05$; Fig. $11 B)$.

\section{Relative separation of the $\mathrm{CS}^{+}$and $\mathrm{CS}^{-}$}

Two different tone frequencies were presented as the $\mathrm{CS}^{+}$and $\mathrm{CS}^{-}$in an attempt to activate two different sets of presynaptic afferents. However, neurons in the auditory thalamus and cortex (which make up the presynaptic neural pool for the cortical cells being recorded) usually respond to a relatively wide range of frequencies at the suprathreshold intensities used here [thalamus: Aitkin (1973), Calford and Webster (1981), and Redies and Brandner (1991); ACx: Phillips and Irvine (1981), Redies et al., (1989), and Schreiner and Sutter (1992)]. Therefore, it is likely that for most of the postsynaptic cells some proportion of afferents was activated by both the $\mathrm{CS}^{+}$and the $\mathrm{CS}^{-}$. The measure of plasticity used here was differential (the index) and only detected plasticity when changes in response to the $\mathrm{CS}^{+}$were different, either in polarity or in magnitude, from changes to the $\mathrm{CS}^{-}$. Afferents that were activated by both the $\mathrm{CS}^{+}$and $\mathrm{CS}^{-}$could not contribute to differential plasticity because any change in the strength of their synapses would affect responses to both tones similarly. Therefore, one would predict that the greater the proportion of afferents activated by both the $\mathrm{CS}^{+}$and $\mathrm{CS}^{-}$, the lower the potential for differential plasticity.

We tested this prediction by determining the relationship between plasticity observed and the relative separation of the $\mathrm{CS}^{+}$ and CS along the dimension of frequency (defined in Fig. 12). The more narrowly separated the $\mathrm{CS}^{+}$and $\mathrm{CS}^{-}$, the greater the proportion of afferents activated by both frequencies (simply because the RFs of the afferent cells have finite effective frequency ranges, such that two narrowly separated frequencies would fit within the RFs of more afferents than would two widely separated frequencies). Figure 12 shows that there was a significant positive correlation between relative separation and magnitude of plasticity $(r=0.64, p<0.003)$, confirming the above prediction.

\section{DISCUSSION}

Understanding how natural events induce physiological plasticity of the neocortex has been approached primarily at two levels. The first level is phenomenological. Such studies are conducted in vivo and relate different types of sensory experiences to different types 


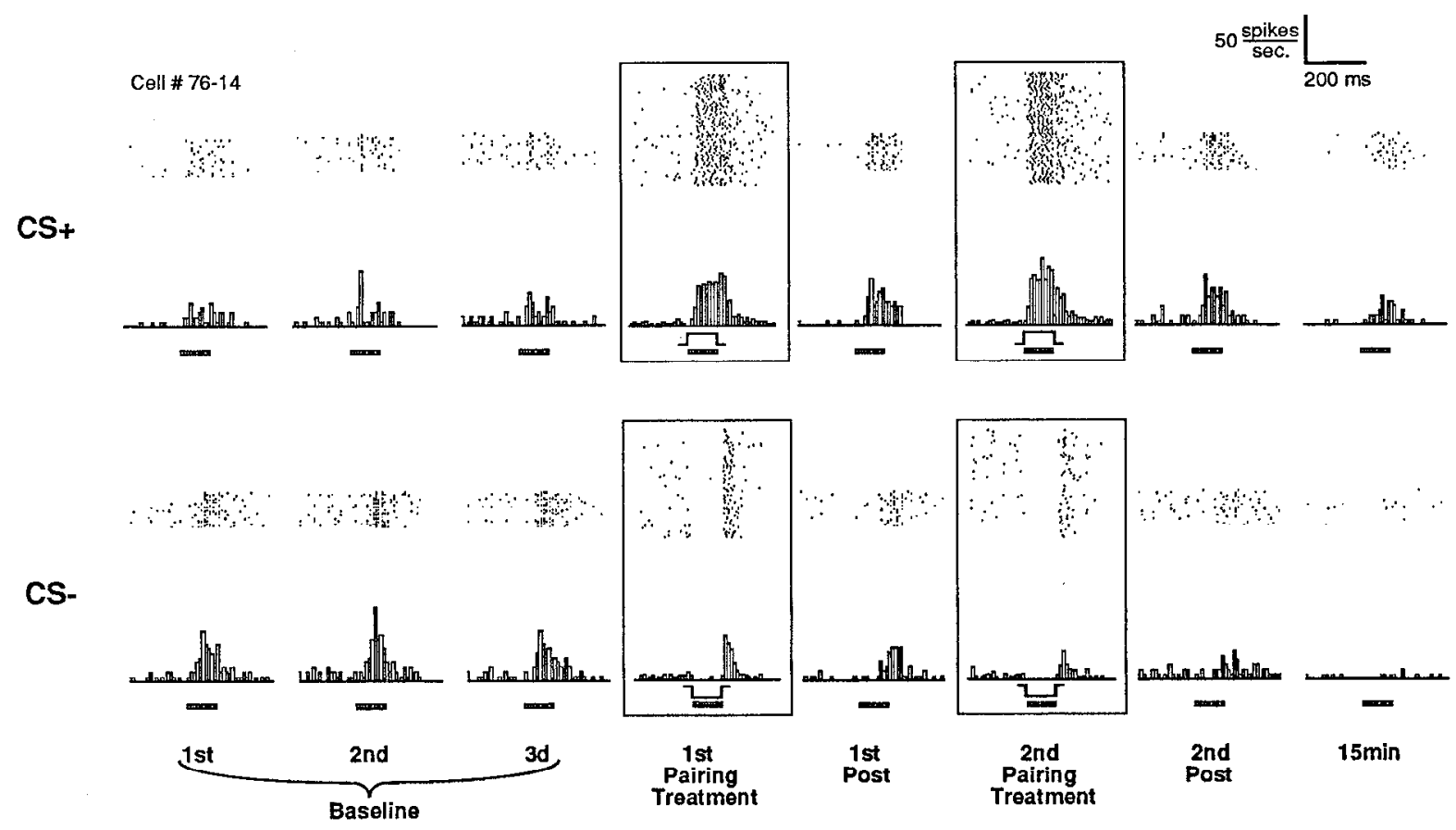

Figure 7. An increase in the $\mathrm{CS}^{+}$versus $\mathrm{CS}^{-}$index attributable to a $\mathrm{CS}^{+}$increase and a $\mathrm{CS}^{-}$decrease. Baseline, 1st Pairing Treatment, 1st Post: Although the responses to both stimuli were diffuse during the baseline, the $\mathrm{CS}^{+}$was consistently weaker than the $\mathrm{CS}^{-}$(mean baseline index, $0.36 \pm 0.03$ ). There were no significant differences among the three blocks of index scores in the baseline $(p>0.05)$. As in Figures 5 and 6 , during the first treatment a significant increase in the $\mathrm{CS}^{+}$and a significant decrease in the $\mathrm{CS}^{-}$were imposed (first treatment index, $0.99 \pm 0.01 ; p<0.0001$ ). Unlike the previous neurons, immediately after the first treatment, there were significant changes for both the $\mathrm{CS}^{+}$and $\mathrm{CS}^{-}$(both $p<0.0001$ ), which resulted in a significant increase in the index (first post measurement, $0.81 \pm 0.04 ; p<0.0001$ ). 2nd Pairing Treatment, 2nd Post, 15min: Additional increases were imposed during the second treatment (index, $0.99 \pm 0.01 ; p<0.0001$ ). Immediately after the second treatment, the index increased further $(0.82 \pm 0.04, p<0.0001$ ), and it increased still further by $15 \mathrm{~min}(0.92 \pm 0.04, p<0.0001)$. By $30 \mathrm{~min}$, it had declined slightly but was still significantly elevated compared with baseline $(0.79 \pm 0.15 ; p<0.0001$; data not shown; see Fig. $8 B)$. (See Figure 5 for orientation and terminology.)

of plasticity. The second level is cellular-mechanistic. They usually are done in vitro and study intracellular and subcellular mechanisms of plasticity. The present work lies within an intermediate, intercellular level, in which cellular interactions thought to be involved in plasticity are examined and tested in vivo (Stryker and Strickland, 1984; Fregnac et al., 1988; Ahissar et al., 1992). The goal of this experiment was to evaluate the role of cellular interactions postulated in the Hebbian hypothesis in experienceinduced RF plasticity in the adult $\mathrm{ACx}$, by testing whether a covariance treatment alone was sufficient for inducing such plasticity. Results indicated that responses of $32 \%$ of the recorded cells were modified significantly by the treatment in the direction predicted by the Hebbian hypothesis, whereas no cells were modified in the nonpredicted direction (120 trial treatments, experiment 2). Several factors related to whether a cell was affected significantly, including state of the cortex during treatment, cortical depth, and relative separation of the two differentially treated afferent inputs (see below).

\section{Rationale and validity of the present approach}

\section{Rationale for the Hebbian hypothesis}

The original logic implicating Hebbian interactions in the induction of RF plasticity in the ACx emerged from the properties of the latter. One such property is activity-dependent afferent specificity. During conditioning, in which presentation of a specific tone frequency is paired with foot shock, cells in the ACx develop increased responses to the paired frequency compared with frequencies that were not presented (Bakin and Weinberger, 1990; Edeline et al., 1990; Recanzone et al., 1993). The specificity of the increases to the afferent pathways that were active during conditioning strongly suggests that the afferent activity is important for induction of the plasticity. Second, differences in plasticity produced by different learning protocols suggest that afferent activity is not the only signal involved. In contrast to conditioning, habituation (repeated presentation of a frequency without reinforcement) induces specific decreases in auditory cortical responses for active afferent pathways (Condon and Weinberger, 1991). Therefore, some neural signal or process must determine whether the functional efficacy of an active afferent will be increased or decreased. By invoking the postsynaptic response magnitude as this critical signal, the Hebbian hypothesis accounts reasonably well for these and other properties of RF plasticity in the ACx (Weinberger, 1995) (see also introductory remarks).

\section{Rationale for the present methods.}

There were several rationales for the specific treatment protocol chosen here to test sufficiency of Hebbian induction mechanisms. First, an in vivo preparation was used to activate cortical afferents through normal channels using sensory stimulation. This allowed direct assessment of tone-evoked responses and RFs. Control of postsynaptic activity was achieved through juxtacellular current stimulation and continuous recording (response increases and decreases; Fig. 2). The juxtacellular method provided a direct postsynaptic manipulation that was highly localized to the recorded cell (Fig. 3), avoiding potential nonspecific effects that could result from antidromic (O'Brien et al., 1977) or orthodromic (Ahissar et al., 1992) manipulations of postsynaptic activity. Finally, a discrimination design (i.e., differentially manipulat- 
A. $91-10$

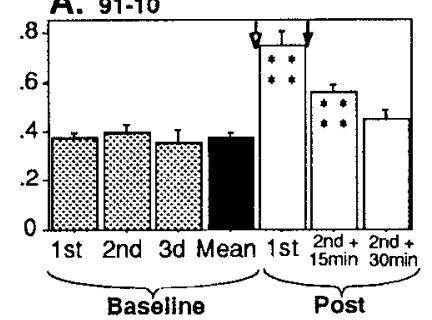

B. $76-14$

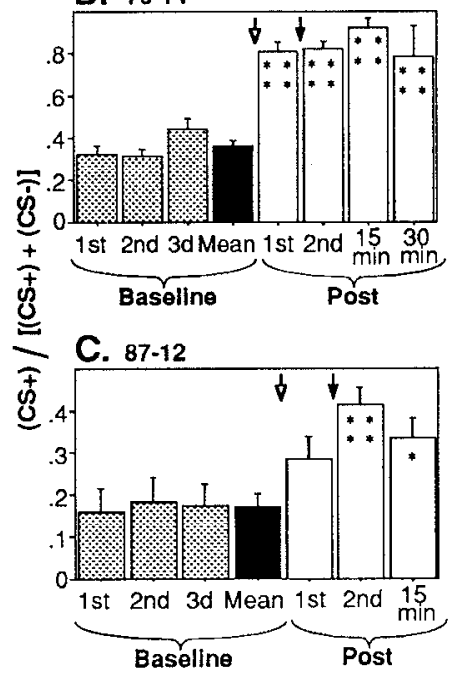

D. $75-09$

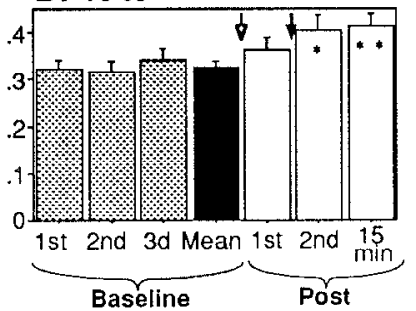

E. $91-14$

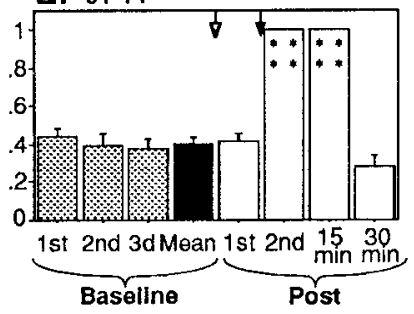

F. $76-11$

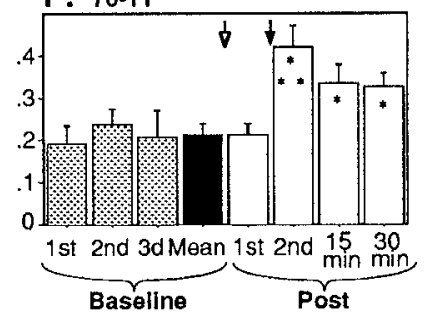

G. $80-18$

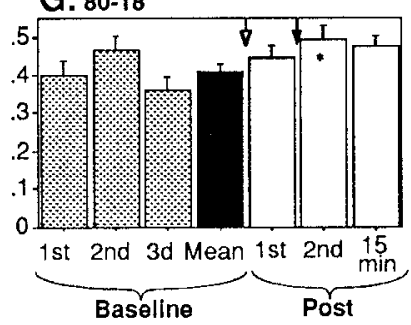

- $p<0.05$

* $p<0.01$

$\therefore p<0.001$

$\because \quad p<0.0001$

$\downarrow$ 1st pairing treatment

$\downarrow$ 2nd pairing treatment

Figure 8. Development and maintenance of the plasticity. Figure 8 depicts all baseline and post $\mathrm{CS}^{+}$versus $\mathrm{CS}^{-}$index values $( \pm \mathrm{SE})$ for the seven cells that exhibited significant plasticity immediately after the second treatment. $C, E$, and $B$ represent the same neurons as in Figures 5, 6, and 7 , respectively (cell numbers shown). For each neuron, the three individual baseline blocks are displayed separately to illustrate their stability (gray bars) and also are collapsed into one block (black bars) for comparison with the post measurements (white bars). Times of first and second treatments are indicated by open and closed arrows, respectively. For cell 91-10, the individual trial data immediately after the second treatment were lost because of computer failure $(A)$. Immediately after the first treatment, two cells had significant increases $(A, B)$, two had nonsignificant but measurable increases $(C, D)$, and three did not change bcyond the rangc scen in the baseline $(E-G)$. With one exception, the effect of the second treatment was to increase the index, regardless of the effect of the first treatment $(B-G)$. Significant plasticity was maintained in six of seven cells for $15 \mathrm{~min}(A-F)$ and in two of four cells that were "held" for $30 \min (B, F)$.

ing postsynaptic responses to two different frequencies) was used for two reasons. First, presenting approximately equal amounts of excitatory and inhibitory current to any given neuron ensured that these stimuli had approximately zero net effect on overall activity, which is considered to be important in models of covariance plasticity (Bear et al., 1987). Second, the differential measure (the index) was designed to control for possible spontaneous fluctuations in postsynaptic excitability that could introduce "noise" into

measurements of plasticity (Fregnac et al., 1992). The index can detect changes in the responses to the $\mathrm{CS}^{+}$and $\mathrm{CS}^{-}$only if those changes are different from one another in polarity or magnitude (see Materials and Methods), indicating that it should be unaffected by general changes in postsynaptic excitability. This was contirmed partially by results from the baseline period (all 38 cells were stable, $p>0.05$ ) (see also Baseline responses in Fig. 8).

\section{Support for the Hebbian hypothesis in the ACx: imposed change in presynaptic-postsynaptic covariance is sufficient to induce RF plasticity}

During the covariance treatment, excitatory and inhibitory juxtacellular currents significantly controlled responses of the postsynaptic cells to the two different tones (Figs. 2, 5-7). After treatment, responses to frequencies paired with increased postsynaptic activity $\left(\mathrm{CS}^{+}\right)$were strengthened compared with frequencies paired with decreased postsynaptic activity $\left(\mathrm{CS}^{-}\right)$, as predicted by the Hebbian hypothesis (Table 1; Figs. 5-9). The number of treatment trials had a strong effect on plasticity. In experiment 2 , only $11 \%$ of cells expressed significant plasticity after 60 trials, whereas $32 \%$ expressed plasticity after 120 trials. The results of experiment 2 alone do not indicate whether these differences were attributable to the additional trials or to the additional $10-15 \mathrm{~min}$ required to accomplish them (Fig. 1). However, in experiment 1 recordings were made for up to $1 \mathrm{hr}$ after the initial 60 trials without further treatment, and no increases in plasticity were seen at later times (Fig. 4A). Therefore, we conclude that the increases in plasticity after additional treatment were attributable to the increased number of trials.

The question is raised whether the treatment trials exerted their influence incrementally or in an all-or-none manner. This question may be important for understanding the functional relevance, as well as the underlying cellular mechanisms, of this type of plasticity. Results from several individual neurons (Figs. 5, 7, $8 B-D$ ) and the group (Figs. $4 A, 9 A$ ) showed detectable (but usually nonsignificant) plasticity after 60 trials, which increased further after 120 trials, thus supporting the incremental hypothesis. Individual data revealed further that the number of trials required to induce statistically significant plasticity varied from cell to cell (compare Fig. $8 A, B$ with $C-G$ ). This raises the possibility that some of the "nonsignificant" cells had the potential for plasticity but simply required more than 120 trials to reach significance. If this were true, then some indication of incremental change would be expected for those cells. In support of this, a majority of nonsignificant response changes occurring after 120 trials $(11 / 15,73 \%)$ were in the direction predicted by the Hebbian hypothesis (Fig. 9B). This leads to the testable prediction that more cells would express significant plasticity if more trials were added.

An important issue relating to any newly described form of plasticity is the duration of the changes. It is clear from individual (Figs. 5-8) and group (Fig. 9) data that when significant plasticity was induced, it lasted at least $15 \mathrm{~min}$. Unfortunately, only four significant cells were "held" for 30 min after the 120 trial treatment because of mechanical instability during the long protocol ( $>80 \mathrm{~min}$ ). Of these, two of four maintained significant levels of plasticity (Fig. 8). Although this shows promise for long-term effects, strong conclusions require a larger sample.

As illustrated in the individual examples (Figs. 5-7), support for the Hebbian hypothesis was provided by increases in response to the $\mathrm{CS}^{+}$, decreases to the $\mathrm{CS}^{-}$, or both. However, when the population as a whole was examined, there was a clear prevalence 
Figure 9. Experiment 2 post-treatment group results. $A$, Mean $\mathrm{CS}^{+}$versus $\mathrm{CS}^{-}$index values $( \pm \mathrm{SE})$ for the baseline and each of the post-treatment periods. Note the nonsignificant increases after the first and second treatments that is maintained through $15 \mathrm{~min}$. Probabilities are results of paired $t$ tests (posts vs baseline, within cell). $B$, Postpairing change in $\mathrm{CS}^{+}$and $\mathrm{CS}^{-}$for all neurons in each period. The $y$ axis shows the change in spike rate for the $\mathrm{CS}^{+}$(each post minus baseline). The $x$ axis shows the change for the $\mathrm{CS}^{-}$. Therefore, a given point represents the effect on the $\mathrm{CS}^{+}$versus the $\mathrm{CS}^{-}$ for a single neuron. Immediately after the first treatment, approximately equal numbers of points were above and below the diagonal, indicating no systematic change across neurons. Immediately after and 15 min after the second treatment, most of the points are located above the diagonal. This indicates that after the second treatment, most neurons had relative increases in favor of $\mathrm{CS}^{+}$compared with the $\mathrm{CS}^{-}$(both large and small changes). Note that the relative increases in the $\mathrm{CS}^{+}$after the second treatment are attributable mainly to absolute decreases for the $\mathrm{CS}^{-}$; most of the points have $\mathrm{CS}^{-}$decreases, but there are approximately equal numbers of increases and decreases for the $\mathrm{CS}^{+}$. Post 2 nd: $\mathrm{CS}^{+}, 11$ of 22 increases and 11 of 22 decreases; $\mathrm{CS}^{-}, 6$ of 22 increases and 16 of 22 decreases. $15 \mathrm{~min}$. Post 2nd: $\mathrm{CS}^{+}, 10$ of 20 increases and 10 of 20 decreases; CS , 7 of 20 increases and 13 of 20 decreases.
A.

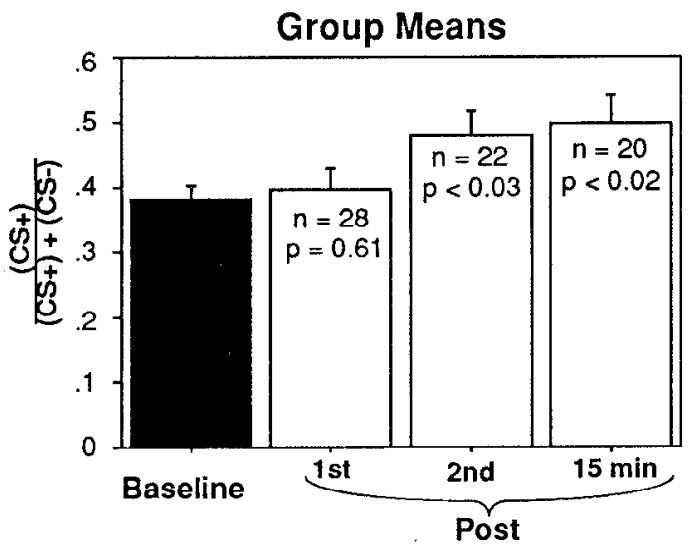

B.

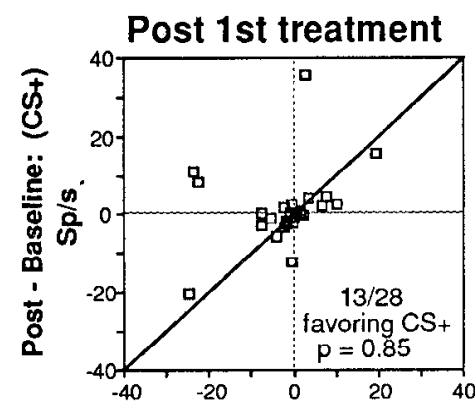

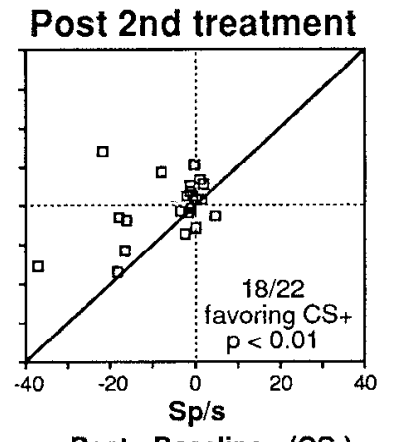

15 min. Post

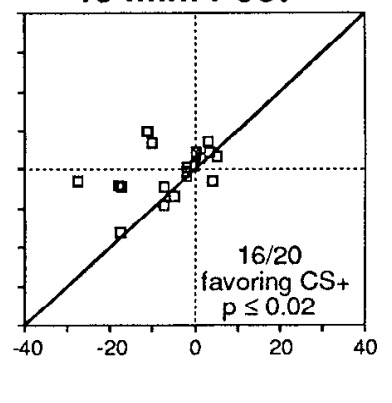

Post - Baseline: (CS-)

of $\mathrm{CS}^{-}$decreases (Fig. 9B). Such decreases suggest synaptic depression, a form of plasticity that recently has come under intense study in the neocortex (for review, see Artola and Singer, 1993; Bear and Malenka, 1994). However, because of limitations of extracellular methods, it is not absolutely clear that decreases in response to the $\mathrm{CS}^{-}$are the result of depression of $\mathrm{CS}^{-}$synapses. Extracellular methods can reveal relative changes in synaptic strength between two or more sets of afferents, as in the present case and in the in vivo experiments of Fregnac and coworkers (see below). However, intracellular recordings are required to determine absolute changes in synaptic strength (Fregnac et al., 1994).

\section{Factors relating to modifications by the covariance treatment}

In the in vivo neocortex, many factors could influence the effect a treatment might have on a given cell. These factors include (1) differences in the "state" of a cell's immediate environment at the time of treatment, (2) intrinsic properties of cells, and (3) unintended differences in treatments themselves. We reported three such factors, one from each category (see below).

\section{Cortical state}

Perhaps the most important factor was cortical state at the time of the treatment. Plasticity was significantly more likely when the EEG was nonsynchronized during treatment than when it was synchronized (Fig. 10). Low-voltage, high-frequency EEG waves, such as those that occur during nonsynchrony, have been associated with increases in excitability and with depolarization of the resting potential in neocortical neurons (Metherate et al., 1992) (for review, see Steriade et al., 1993). Therefore, a trivial potential explanation for the present EEG findings might have been that cells treated in the nonsynchronous state were more excited and, therefore, had greater changes in covariance during treatment, producing greater effects. However, this was not the case; there were no differences in the magnitude of covariance treatment strengths between the EEG groups. This implies that covariance treatment levels that were insufficient to produce plasticity during synchrony were sufficient to do so during nonsynchrony.

This apparent "gating" of plasticity by cortical state (or associated factors) is broadly consistent with the effects of "behavior" on covariance plasticity observed in the $\mathrm{ACx}$ of awake monkeys. Ahissar et al. (1992) demonstrated that the cross-correlation between two cells in the ACx could be modified by a covariance treatment in which a spike in one cell (presynaptic cell) was followed by a sound that either excited or inhibited the other cell (postsynaptic cell). The modifications, which lasted 1-13 min after the treatment, were in the direction predicted by the Hebbian hypothesis. Moreover, they were gated by "behavior" much as plasticity in the present study was gated by cortical state. The modifications were significantly greater for a given covariance treatment strength when the monkey attended to sounds [to receive rewards (behavior)] than when it sat passively. The common gating phenomena suggest common underlying mechanisms. In this respect, it is interesting that at least one cortically projecting neuromodulatory system (the basal forebrain cholinergic system) exhibits high activity during both nonsynchronous EEG and reinforced behaviors similar to those in Ahissar et al. (1992) (see also Richardson and DeLong, 1988). Neuromodulatory gating influences also have been proposed to account for differences in plasticity found in vitro versus in vivo (Nowicky et al., 1992). For example, in the motor cortex of awake animals, covariance treatments produce significant plasticity in 58\% of recorded cells (Baranyi et al., 1991). However, in the in vitro motor cortex, where 


\section{A. Examples of Each EEG Category}

1. Desynchronized

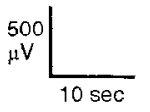

2. Synchronized

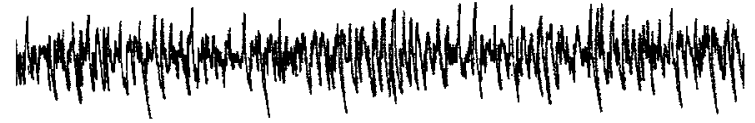

3. Transition

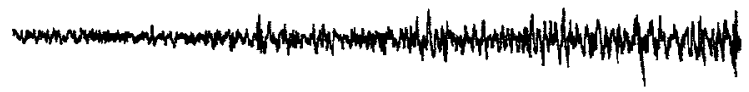

\section{B. Effect of EEG During Treatment on Plasticity}

\begin{tabular}{|c|c|c|}
\cline { 2 - 3 } \multicolumn{1}{c|}{} & Synchronized & Nonsynchronized \\
\hline Significant Increase & 2 & 5 \\
\hline No Significant Change & 11 & 4 \\
\hline
\end{tabular}

$x^{2}=3.96, d f=1, p<0.05$

Figure 10. The effect of cortical EEG state during treatment. $A$, Representative examples of each EEG category. All threc were recorded from the same electrode, located on the cortical surface of one animal, in which the EEG exhibited a transition from a desynchronized to a synchronized state (single-ended recordings, bandpass $1-75 \mathrm{~Hz}$, written to polygraph). The top record (1) is a desynchronized EEG, dominated by smallamplitude $(<100 \mu \mathrm{V})$, high-frequency $(>5 \mathrm{~Hz})$ waves. The middle record (2) is a synchronized EEG, characterized by large-amplitude $(>300 \mu \mathrm{V})$, low-frequency $(1-5 \mathrm{~Hz}$ ) waves. The bottom record (3) is a transition state, in which the EEG gradually shifted from a desynchronized to a synchronized state. Shifts from synchronized to desynchronized states (data not shown) also were categorized as transitions. The EEG recording electrodes actually were placed contralateral to the auditory cortical loci from which cellular activities were recorded (see Materials and Methods) However, based on pilot experiments, we are reasonably confident that the recorded EEGs reflect, at least on the gross level cxamined here, the EEGs of the cortical regions from which cells were recorded. See Livingstone and Hubel (1981) for repeated examples showing that gross EEG is very similar between regions of the neocortex that are separated by several centimeters-distances greater than those involved here. $B$, The $\chi^{2}$ table shows the probability of plasticity as a function of the EEG state during the treatment. Desynchronized and transition states were combined into a single nonsynchronized group and compared with the fully synchronized group. Recall that no significant decreases in the index occurred immediately after the second treatment. Note the significantly higher probability of plasticity in the nonsynchronized compared with the synchronized group ( $p<0.05$; see Results).

the influences of subcortical neuromodulatory inputs are removed, very similar treatments produce plasticity in only $14 \%$ of recorded cells (Bindman et al., 1988).

\section{Cortical depth}

A second significant factor in this study was depth of the postsynaptic cell from the cortical surface. Cells with significant plasticity were found clustered in the middle cortical depths (estimated layer IV and upper layer V; see Fig. 11). This is in agreement with locations where learning-induced plasticity has been observed (Bakin and Weinberger, 1990). However, it contrasts with other studies of plasticity in the adult sensory neocortex that have found
A.

B.

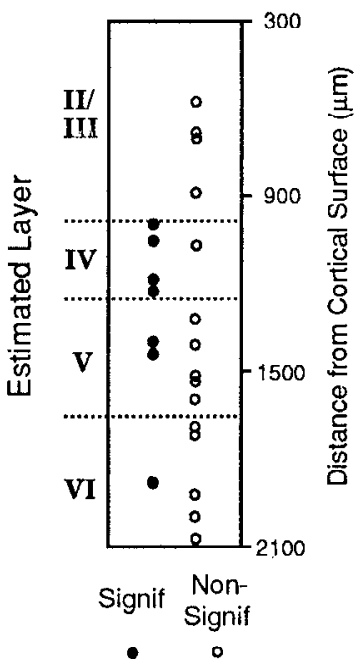

Probability of Plasticity in Layers IV \& V vs. Other Layers

\begin{tabular}{|c|c|c|}
\cline { 2 - 3 } \multicolumn{1}{c|}{} & $\begin{array}{c}\text { Layers } \\
\text { IV \& V }\end{array}$ & $\begin{array}{c}\text { Other } \\
\text { Layers }\end{array}$ \\
\hline Sig. Increase & 6 & 1 \\
\hline Not Sig. & 6 & 9 \\
\hline
\end{tabular}

Figure 11. Fffect of cortical depth on plasticity. $A$, Depth versus effect; each dot represents the position of a cell from the cortical surface, as measured from a microdrive (right axis). The horizontal broken lines indicate depths of laminar boundaries estimated from histological analysis in previous experiments (N. Weinberger and J. Winer, unpublished observations). Filled dots represent the seven cells with significant increases after 120 treatment trials. Open dots represent cells that did not show significant plasticity. Notice that cells with significant increases are concentrated in the middle depths (layer IV and upper layer V). $B, \chi^{2}$ analysis revealed that the middle cortical layers (IV and V), when considered as a group, had a significantly greater probability of plasticity than other layers. Furthermore, layer IV (by itself) had a significantly greater probability of plasticity than the other layers $\left(\chi^{2}=6.92, \mathrm{df}=1, p<0.01\right.$; data not shown).

greater incidence of plasticity outside the middle layers (Diamond et al., 1994) (for a review of the laminar distribution of long-term potentiation, see Tsumoto, 1990). There is considerable heterogeneity among characteristics of cells in layers IV and V, including morphology, physiology, and connectivity (see above). Therefore, additional information is needed to determine the characteristics of cells in these layers that caused them to be selectively susceptible to the covariance treatment.

\section{Relative $\mathrm{CS}^{+}$versus $\mathrm{CS}^{-}$separation}

The third factor found to affect plasticity was the relative separation between the $\mathrm{CS}^{+}$and $\mathrm{CS}^{-}$along the dimension of acoustic frequency - the narrower the separation, the lower the magnitude of plasticity (Fig. 12). Differential plasticity requires that the $\mathrm{CS}^{+}$ and $\mathrm{CS}^{-}$tones activate distinct afferents. The greatest proportion of distinct afferents would occur when the two frequencies were most separate (explained in Results). Therefore, the relationship between plasticity and separation was predicted (see above). These results lead to an additional prediction that the overall probability of significant plasticity would increase if the separation could be increased across all cells.

\section{Relation to previous studies of covariance-induced plasticity in the neocortex}

In vivo covariance-induced $R F$ plasticity

The present experiments are very similar to those of Shulz and Fregnac (1992) and Fregnac et al. (1992), who determined the effects of a differential covariance treatment in visual cortex using visual stimuli for afferent activation and juxtacellular current for 


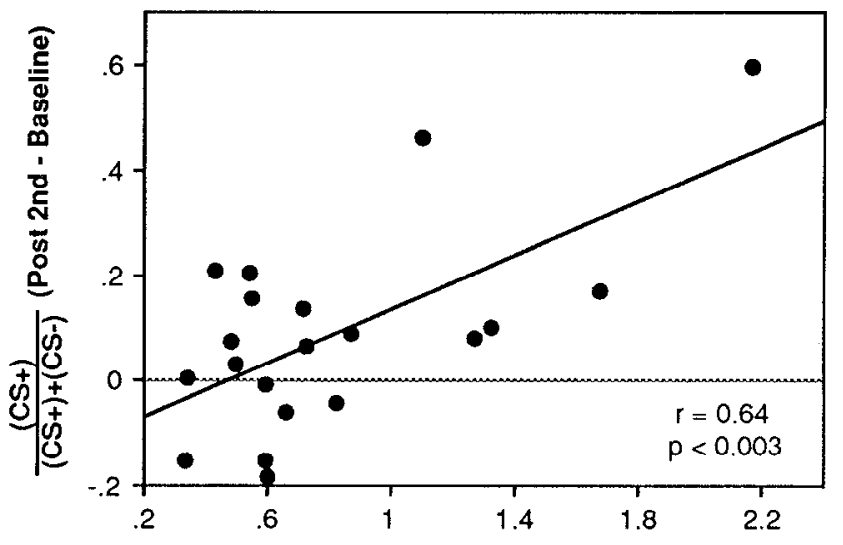

Relative Separation (CS+ vs. CS-)

Figure 12. Effect of relative separation of the $\mathrm{CS}^{+}$versus $\mathrm{CS}^{-}$on plasticity. The $y$ axis represents the magnitude of the plasticity immediately after the second pairing. The $x$ axis represents the relative separation of the $\mathrm{CS}^{+}$versus the $\mathrm{CS}^{-}$, calculated as:

$$
\text { Relative separation }\left(\mathrm{CS}^{+} \text {vs } \mathrm{CS}^{-}\right)=\frac{\text { frequency separation }\left(\mathrm{CS}^{+} \text {vs } \mathrm{CS}^{-}\right)}{\text {bandwidth (at treatment intensity) }}
$$

Bandwidth was obtained during the initial RF characterization (see Fig. 1) and calculated as the distance between the low and high frequencies eliciting responses that were $50 \%$ of the maximum response. Frequency separation and bandwidth were measured in octaves. High values on the $x$ axis indicate a relatively large separation of the $\mathrm{CS}^{+}$and $\mathrm{CS}^{-}$and, therefore, minimal proportions of afferents activated by both frequencies (afferent sharing). Low values indicate little separation and, therefore, greater afferent sharing. Note the strong correlation between relative separation and plasticity $(r=0.64, p<0.003)$. The rationale for dividing by bandwidth, rather than simply using the frequency separation, was to control for variables such as intensity. At high intensities, the range of frequencies capable of exciting a given afferent to $\mathrm{ACx}$ generally would be broader than at low intensities, so that the proportion of afferents shared by any given $\mathrm{CS}^{+}$and $\mathrm{CS}^{-}$would be larger at high than at low intensities. Thus, frequency separation alone tends to underestimate the amount of afferent sharing for high intensities compared with low intensities. Fortunately, bandwidth of the recorded cell also would increase generally with intensity (in parallel with the afferents). This would decrease relative separation values for high intensities (because of the increased denominator), increasing the estimate of sharing and thereby controlling for the effects of intensity. Bandwidth was used as a normalization factor rather than intensity per se to control for other variables that also could decouple the relationship between afferent sharing and frequency separation. For example, although efforts were made to keep depth of anesthesia as consistcnt as possible, it may have varicd slightly among cells and animals. Urethane produces dose-dependent increases in thresholds for acoustic responses in the cochlea (Pickles, 1984). Presumably, this effect is relayed to auditory forebrain neurons, causing decreases in the proportion of afferents shared by a given $\mathrm{CS}^{+}$and $\mathrm{CS}^{-}$. Thus, frequency separation alone would overestimate the amount of sharing for cells recorded under very deep anesthesia versus moderate anesthesia, even at a constant intensity. However, bandwidths of the recorded cell also would tend to decrease with deeper levels of anesthesia. As a result, relative separation values would increase, decreasing the estimate of sharing, thus controlling for depth of anesthesia.

postsynaptic control. Using the same relative measure as in the present experiment (i.e., the index), they also found that approximately one-third of recorded cells expressed significant plasticity in the direction predicted by the Hebbian hypothesis, whereas $<5 \%$ changed in the nonpredicted direction. Similarities extended beyond the main effects. For example, Fregnac et al. (1992) also observed the greatest plasticity when the two afferent stimuli were most separated. Moreover, they observed plasticity in adult (as well as in young) animals, despite the fact that the types of RF plasticity they examined only can be induced by experience during development. The similarities are exciting, because they suggest common principles of plasticity among different neocortical sensory regions. However, there are differences between regions that also could be important. For example, no effects of cortical depth were observed in the visual cortical experiments. Morcover, Fregnac et al. (1992) found the greatest magnitude of plasticity in broadly tuned cells, whereas breadth of tuning had no effect in our experiments ( $p>0.05, t$ test, significant vs nonsignificant cells).

\section{Synaptic plasticity}

The relative $\mathrm{CS}^{+}$versus $\mathrm{CS}^{-}$increases in the present findings are consistent with (and potentially could be caused by) three different types of synaptic plasticity: (1) homosynaptic potentiation of $\mathrm{CS}^{+}$synapses; (2) homosynaptic depression of $\mathrm{CS}^{-}$synapses; and (3) heterosynaptic depression of $\mathrm{CS}^{-}$synapses. Homosynaptic potentiation has been documented widely in the adult neocortex, including the ACx (Kudoh and Shibuki, 1994) (for review, see Tsumoto, 1990; Bear and Kirkwood, 1993). In most areas tested so far, it can be induced by a protocol that is analogous with the $\mathrm{CS}^{+}$portion of the present protocol [i.e., pairing low-frequency afferent stimulation with strong postsynaptic activity (Baranyi and Feher, 1981; Bindman et al., 1988; Kossel et al., 1990; Hirsch and Gilbert, 1993; Fregnac et al., 1994; Kirkwood and Bear, 1994a; Yoshimura and Tsumoto, 1994)], supporting the idea that homosynaptic potentiation could underlie some of the present results.

Homosynaptic depression in the adult neocortex also has been reported by a number of groups (Artola et al., 1990; Yoshimura et al., 1991; Kirkwood and Bear, 1994b), but the potential relationship with the present results is tenuous. These depression protocols appear to require that postsynaptic responses (to afferent input) be more depolarized than during normal synaptic transmission. However, in the present protocol it appears that negative current caused the postsynaptic responses (to $\mathrm{CS}^{-}$afferents) to be more hyperpolarized than during normal transmission, as indicated by the following rationale. First, spike responses to the $\mathrm{CS}^{-}$ tone were reduced strongly during treatment for all cells (Fig. 2). Second, robust rebound spike bursts were seen consistently for some cells after offset of negative current $(n=3$; data not shown previously). There were no such responses to tone offset for these cells when the tones were presented alone, indicating that the negative juxtacellular current was responsible for the rebound excitation and suggesting that the negative current caused intracellular hyperpolarization. To our knowledge, the only neocortical dcmonstration of homosynaptic depression that is directly analogous with the present $\mathrm{CS}^{-}$protocol (i.e., pairing afferent activity with postsynaptic hyperpolarization) is by Fregnac et al. (1994), who observed that depression was short-lived (for a potentially related protocol, see Kato, 1993).

Finally, heterosynaptic depression, induced by strong postsynaptic depolarization in the absence of synaptic activity (analogous with the condition of the inactive $\mathrm{CS}^{-}$synapses during the $\mathrm{CS}^{+}$ portion of the present protocol), has been investigated sparsely in the neocortex. This is despite the fact that it has been investigated widely in the hippocampus (Lynch et al., 1977; Levy and Steward, 1979; Abraham and Goddard, 1983; Bradler and Barrionuevo, 1990; Pockett et al., 1990; Christie and Abraham, 1992; Debanne et al., 1994) and that the original theoretical formulations of Hebbian processes in neocortical RF plasticity involved heterosynaptic depression exclusively (Stent, 1973). Results of the 
explicit tests that do exist have been somewhat variable. For example, Fregnac et al. (1994) observed that responses to afferent inputs that were inactive during strong postsynaptic activity became functionally depressed, but only for a short time (generally $<15 \mathrm{~min}$ ). On the other hand, Sil'kis et al. (1994) and Volgushev et al. (1994) found long-lasting effects (generally $>30 \mathrm{~min}$ ). Furthermore, Volgushev et al. (1994) found that strong postsynaptic depolarization in the absence of synaptic activity actually caused heterosynaptic potentiation more often than depression. It will be important in future experiments to determine which, if any, of the three types of synaptic plasticity described above is involved in the kind of covariance plasticity observed in the present results.

\section{Functional implications}

Traditionally, the primary sensory neocortex has been thought to be relatively static in the adult, in contrast to its highly dynamic state during development. However, under specific circumstances, plasticity can be induced in the adult sensory neocortex (see above). For example, it has been known for more than 40 years that physiological properties of the adult auditory cortex are modified by learning (for review, see Weinberger and Diamond, 1987). The previously obscure relationship of these learning effects with the larger sphere of literature of sensory physiology now is being clarified through studics of metabolic activity, representational maps, and RFs (Merzenich et al., 1990; Scheich, 1991; Gonzalez-Lima, 1992). These studies have revealed that learning increases representation of behaviorally important sounds relative to other acoustic stimuli (for review, see Weinberger, 1993).

Despite the progress made in characterizing these phenomena, the mechanisms by which adult learning induces these modifications remain unclear. The present findings address this issue by demonstrating that covariance manipulations (in the absence of behavioral learning) are sufficient to induce RF plasticity in the $\mathrm{ACx}$, thus providing support for Hebbian induction mechanisms. An additional logical test would be to determine whether Hebbian mechanisms are necessary for learning-induced plasticity. This could be accomplished by interfering, pharmacologically or electrically, with covariance (between postsynaptic cortical cells and their presynaptic afferents) during auditory learning, as was done previously for other forms of plasticity (Carew et al., 1984; Malinow and Miller, 1986; Reiter and Stryker, 1988; Bear et al., 1990; Schlaggar et al., 1993). Demonstrating necessity, combined with the present demonstration of sufficiency, would strengthen greatly the hypothesis that Hebbian mechanisms are involved in the induction of learning-induced RF plasticity in the ACx. It also would support a recent model of ACx plasticity that involves such mechanisms critically (Weinberger et al., 1990).

It is noteworthy that Hebbian mechanisms very similar to those found here to he sufficient for inducing plasticity in adult $\mathrm{ACx}$ previously have received broad support for developmental plasticity in the visual cortex (for review, see Rauschecker, 1991). This suggests the involvement of common processes in the induction of adult and developing sensory cortical plasticity. However, many forms of experience-induced cortical plasticity observed in development do not continue into adulthood (Belford and Killackey, 1980; Sherman and Spear, 1982) (see also Crair and Malenka, 1995). This apparent contradiction may be resolved partly by considering the present gating effects of cortical state. These results suggest that covariance processes are relatively ineffective in producing plasticity in the adult ACx, except under specific circumstances, one of these being a nonsynchronous cortical state (i.e., relatively low-voltage, high-frequency EEG activity). It prob- ably is not coincidental that one of the rare forms of cxperience consistently reported to induce plasticity in adult sensory cortexlearning - is characterized by similar EEG activity (John, 1961; Morrell, 1961). Understanding the mechanisms by which staterelated factors might gate covariance plasticity will be both interesting and challenging.

\section{REFERENCES}

Abraham WC, Goddard GV (1983) Asymmetric relationships between homosynaptic long-term potentiation and heterosynaptic long-term depression. Nature 305:717-719.

Ahissar E, Ahissar M (1994) Plasticity in auditory cortical circuitry. Curr Opin Neurobiol 4:580-587.

Ahissar E, Vaadia E, Ahissar M, Bergman H, Arieli A, Abeles M (1992) Dependence of cortical plasticity on correlated activity of single neurons and on behavioral context. Science 257:1412-1415.

Aitkin LM (1973) Medial geniculate body of the cat: responses to tonal stimuli of neurons in medial division. J Neurophysiol 36:275-283.

Andrew RD, Fagan M' (1990) A technique for controlling the membrane potential of neurons during unit recording. J Neurosci Methods 33:55-60.

Artola A, Singer W (1993) Long-tern depression of excitatory synaplic transmission and its relationship to long-term potentiation. Trends Neurosci 16:480-487.

Artola A, Brocher S, singer W (1990) Different voltage-dependent thresholds for inducing long-term depression and long-term potentiation in slices of rat visual cortex. Nature 347:69-72.

Bakin JS, Weinberger NM (1990) Classical conditioning induces CSspecific receptive field plasticity in the auditory cortex of the guinea pig. Brain Res 536:271-286.

Baranyi A, Feher O (1981) Long-term facilitation of excitatory synaptic transmission in single motor cortical neurones of the cat produced by. repetitive pairing of synaptic potentials and action potentials following intracellular stimulation. Neurosci Lett 23:303-308.

Baranyi A, Szente M, Woody C (1991) Properties of associative longlasting potentiation induced by cellular conditioning in the nolor cortex of conscious cats. Neuroscience 42:321-334.

Bear MF, Kirkwood A (1993) Neocortical long-term potentiation. Curr Opin Neurobiol 3:197-202.

Bear MF, Malenka RC (1994) Synaptic plasticity: LTP and LTD. Curr Opin Neurobiol 4:389-399.

Bear MF, Singer W (1986) Modulation of visual cortical plasticity by acetylcholine and noradrenaline. Nature 320:172-176.

Bear MF, Cooper LN, Ebner FF (1987) A physiological basis for a theory of synapse modification. Science 237:42-48.

Bear MF, Kleinschmidt FA, Gu QA, Singer W (1990) Disruption of experience-dependent synaptic modifications in striate cortex by infu sion of an NMDA receptor antagonist. J Neurosci 10:909-925.

Belford GR, Killackey HP (1980) The sensitive period in the development of the trigeminal system of the meonatal rat. J Comp Neurol 193:335-350.

Berridge CW, Foote SL (1991) Effects of locus coeruleus activation on electroencephalographic activity in neocortex and hippocampus. J Neurosci 11:3135-3145.

Bienenstock EL, Cooper LN, Munro PW (1982) Theory for the development of neuron selectivity: orientation specificity and binocular interaction in visual cortex. J Neurosci 2:32-48.

Bienenstock E, Fregnac Y, Thorpe S (1983) Ionophoretic clamp of activity in visual cortical neurons in the cat: a test of Hebb's hypothesis. $\mathbf{J}$ Physiol (Lond) 345:123P.

Bindman LJ, Murphy PSJ, Pockett S (1988) Postsynaptic control of the induction of long-term changes in efficacy of transmission at neocortical synapses in slices of rat brain. J Neurophysiol 60:1053-1065.

Blakemore C, Cooper GF (1970) Development of the brain depends on the visual environment. Nature 228:477-478.

Blanton MG, Lo Turco JJ, Kriegstein AR (1989) Whole cell recording from neurons in slices of reptilian and mammalian cerebral cortex. $\mathrm{J}$ Neurosci Methods 30:203-210.

Bradler JE, Barrionuevo G (1990) Heterosynaptic correlates of longterm potentiation induction in hippocampal CA3 neurons. Neuroscience 35:265-271.

Brugge JF, Merzenich MM (1973) Responses of neurons in auditory cortex of the macaque monkey to monaural and binaural stimulation. J Neurophysiol 36:1138-1158. 
Buzsaki G, Bickford RG, Ponomareff G, Thal LJ, Mandel R, Gage FH (1988) Nucleus basalis and thalamic control of neocortical activity in the freely moving rat. J Neurosci 8:4007-4026.

Calford MB, Webster WR (1981) Auditory representation within principal division of cat medial geniculate body: an electrophysiology study. $J$ Neurophysiol 45:1013-1028.

Carew T, Hawkins R, Abrams T, Kandel E (1984) A test of Hebb's postulate at identified synapses which mediate classical conditioning in Aplysia. J Neurosci 4:1217-1224.

Christie BR, Abraham WC (1992) NMDA-Dependent heterosynaptic long-term depression in the dentate gyrus of anaesthetized rats. Synapse $10: 1-6$.

Clothiaux EE, Bear MF, Cooper LN (1991) Synaptic plasticity in visual cortex: comparison of theory with experiment. J Neurophysiol 66:1785 1804.

Condon C, Weinberger NM (1991) Habituation produces frequencyspecific plasticity of receptive fields in auditory cortex. Behav Neurosci 105:416-430.

Connors BW (1994) Intrinsic neuronal physiology and the functions, dysfunctions and development of neocortex. Prog Brain Res 102:195-203.

Crair MC, Malenka RC (1995) A critical period for long-term potentiation at thalamocortical synapses. Nature 375:325-328.

Cruikshank SJ, Weinberger NM (1993) Induction of auditory cortical receptive field plasticity: Hebb rules? Soc Neurosci Abstr 19:164.

Cruikshank SJ, Edeline JM, Weinberger NM (1992) Stimulation at a site of auditory-somatosensory convergenee in the medial geniculate nucleus is an effective unconditioned stimulus for fear conditioning. Behav Neurosci 106:471-483.

Dan Y, Poo M-M (1992) Hebbian depression of isolated neuromuscular synapses in vitro. Science $256: 1570-1573$.

Debanne D, Gahwiler BH, Thompson SM (1994) Asynchronous pre- and postsynaptic activity induces associative long-term depression in area CA1 of the rat hippocampus in vitro. Proc Natl Acad Sci USA 91:1148-1152.

Delacour J, Houcine O, Costa JC (1990) Evidence for a cholinergic mechanism of "learned" changes in the responses of barrel field neurons of the awakc and undrugged rat. Neuroscience 34:1-8.

Diamond ME, Huang W, Ebner FF (1994) Laminar comparison of somatosensory cortical plasticity. Science 265:1885-1888.

Edeline J-M, Hars B, Maho C, Hennevin E (1994) I'ransient and prolonged facilitation of tone-evoked responses induced by basal forebrain stimulations in the rat auditory cortex. Exp Brain Res 97:373-386.

Edeline J, Neuenschwander EL, Massioui N, Dutrieux G (1990) Frequency-specific cellular changes in the auditory system during acquisition and reversal of discriminative conditioning. $J$ Psychobiol 18:382-393.

Fregnac Y, Shulz D (1994) Models of synaptic plasticity and cellular analogs of learning in the developing and adult vertebrate visual cortex. In: Advances in neural and behavioral development, Vol 4 (Casagrande V, Shinkman P, eds), pp 97-109. Norwood, NJ: Ablex.

Fregnac Y, Burke JP, Smith D, Friedlander MJ (1994) Temporal covariance of pre- and postsynaptic activity regulates functional connectivity in the visual cortex. J Neurophysiol 71:1403-1421.

Fregnac Y, Shultz D, Thorpe S, Bienenstock E (1988) A cellular analogue of visual cortical plasticity. Nature 333:367-370.

Fregnac Y, Shultz D, Thorpe S, Bienenstock E (1992) Cellular analogs of visual cortical epigenesis. I. Plasticity of orientation selectivity. J Neurosci 12:1280-1300.

Gerken GM (1984) A systens approach to the relationship between the ear and central auditory mechanisms. Adv Audiol 1:30-52.

Gilbert CD (1993) Rapid dynamic changes in adult cerebral cortex. Curr Opin Neurobiol 3:100-103.

Gonzalez-Lima F (1992) Brain imaging of auditory learning functions in rats: studies with fluorodeoxyglucose autoradiography and cytochrome oxidase histochemistry. In: Advances in metabolic mapping techniques for brain imaging of behavioral and learning functions (Gonzalez-Lima F, Finkenstadt T, Scheich H, eds). Boston: Dordrecht.

Greuel JM, Luhmann HJ, Singer W (1988) Pharmacological induction of use-dependent receptive field modification in the visual cortex. Science 24:74-77.

Hamill OP, Marty A, Neher E, Sakmann B, Sigworth FJ (1981) Improved patch-clamp techniques for high-resolution current recording from cells and cell-free membrane patches. Pflügers Arch 391:85-100.

Hebb DO (1949) Organization of behavior. New York: Wiley.
Hirsch HVB, Spinelli DN (1970) Visual experience modifies distributions of horizontally and vertically oriented receptive fields in cats. Science 168:869-871.

Hirsch JA, Gilbert CD (1993) Long-term changes in synaptic strength along specific intrinsic pathways in the cat visual cortex. J Physiol (Lond) 461:247-262.

John ER (1961) High nervous functions: brain functions and learning. Annu Rev Physiol 23:451-484.

Jones EG (1984) Identification and classification of intrinsic circuit elements in the neocortex. In: Dynamic aspects of neocortical function (Edelman GM, Gall WE, Cowan M, eds), pp 7-40. New York: Wiley.

Juliano SL, Ma W, Eslin D (1991) Cholinergic depletion prevents expansion of topographic maps in somatosensory cortex. Proc Natl Acad Sci USA 88:780-784.

Kaas JH (1991) Plasticity of sensory and motor maps in adult mammals. Annu Rev Neurosci 14:137-167.

Kasamatsu T, Watabe K, Heggelund P, Scholler E (1985) Plasticity in cat visual cortex restored by electrical stimulation of the locus coeruleus. Neurosci Res 2:365-386.

Kato N (1993) Dependence of long-term depression on postsynaptic metabotropic glutamate receptors in visual cortex. Proc Natl Acad Sci USA 90:3650-3654.

Kelso S, Ganong A, Brown T (1986) Hebbian synapses in hippocampus. Proc Natl Acad Sci USA 83:5326-5330.

Kirkwood A, Bear MF (1994a) Hebbian synapses in visual cortex. J Neurosci 14:1634-1645.

Kirkwood A, Bear MF (1994b) Homosynaptic long-term depression in the visual cortex. J Neurosci 14:3404-3412.

Kitzes LM, Doherty D (1994) Influence of callosal activity on units in the auditory cortex of ferret (Mustela putorius). J Neurophysiol 71:1740-51.

Kossel A, Bonhoeffer T, Bolz J (1990) Non-Hebbian synapses in rat visual cortex. NeuroReport 1:115-118.

Kudoh M, Shibuki K (1994) Long-term potentiation in the auditory cortex of adult rats. Neurosci Lett 171:21-23.

Levy WB, Steward O (1979) Synapses as associative memory elements in the hippocampal formation. Brain Res 175:233-245.

Lin XY, Glanzman DL (1994) IIebbian induction of long-term potentiation of Aplysia sensorimotor synapses: partial requirement for activation of an NMDA-related receptor. Proc R Soc Lond (Biol) 255:215-221.

Livingstone MS, Hubel DH (1981) Effects of sleep and arousal on the processing of visual information in the cat. Nature 291:554-561.

Lynch GS, Dunwiddie T, Gribkoff V (1977) Heterosynaptic depression: a postsynaptic correlate of long-term potentiation. Nature 266:737-739.

Maggi CA, Meli A (1986) Suitability of urethane anesthesia for physiopharmacological investigations in various systems. I. General considerations. Experientia 42:109-114.

Maldonado P, Gerstein G (1992) Cortical plasticity and neuronal assemblies in rat auditory cortex. Soc Neurosci Abstr 18:148.

Malinow R, Miller J (1986) Postsynaptic hyperpolarization during conditioning reversibly blocks induction of long-term potentiation. Nature 320:529-530.

Merzenich MM, Jenkins WM (1993) Reorganization of cortical representations of the hand following alterations of skin inputs induced by nerve injury, skin island transfers, and experience. $\mathrm{J}$ Hand Ther 6:89-104.

Merzenich MM, Sameshima K (1993) Cortical plasticity and memory. Curr Opin Neurobiol 3:187-196.

Merzenich MM, Recanzone GH, Jenkins WM, Grajski KA (1990) Adaptive mechanisms in cortical networks underlying cortical contributions to learning and nondeclarative memory. Cold Spring Harbor Symp Quant Biol 55:873-887.

Metherate R, Weinberger NM (1989) Acetylcholine produces stimulusspecific receptive field alterations in cat auditory cortex. Brain Res 480:372-377.

Metherate R, Cox CL, Ashe JH (1992) Cellular bases of neocortical activation: modulation of neuronal oscillations by the nucleus basalis and endogenous acetylcholine. J Neurosci 12:4701-4711.

Morreli F (1961) Electrophysiological contributions to the neural basis of learning. Physiol Rev 41:443-494.

Nowicky AV, Christofi G, Bindman LJ (1992) Investigation of $\beta$-adrenergic modulation of synaptic transmission and postsynaptic induction of associative LTP in layer V neurons in slices of rat sensorimotor cortex. Neurosci Lett 137:270-274. 
O'Brien JH, Wilder MB, Stevens CD (1977) Conditioning of cortical neurons in cats with antidromic activation as the unconditioned stimulus. J Comp Physiol Psychol 91:918-929.

Phillips DP, Irvine DR (1981) Responses of single ncurons in physiologically defined primary auditory cortex (AI) of the cat: frequency tuning and responses to intensity. J Neurophysiol 45:48-58.

Pickles JO (1984) Frequency threshold curves and simultaneous masking functions in high-threshold, broadly tuned, fibres of the guinea pig auditory nerve. Hear Res 16:91-99.

Pockett S, Brookes NH, Bindman LJ (1990) Long-term depression at synapses in slices of rat hippocampus can be induced by bursts of postsynaptic activity. Exp Brain Res 80:196-200.

Ranck Jr J (1975) Which elements are excited in electrical stimulation of mammalian central nervous system? A review. Brain Res 98:417-440.

Rasmusson DD, Dykes RW (1988) Long-term enhancement of evoked potentials in cat somatosensory cortex produced by co-activation of the basal forebrain and cutaneous receptors. Exp Brain Res 70:276-286.

Rauschecker JP (1991) Mechanisms of visual plasticity: Hebb synapses, NMDA receptors, and beyond. Physiol Rev 71:587-615.

Rauschecker JP, Singer W (1981) The effects of early visual experience on the cat's visual cortex and their possible explanation by Hebb synapses. J Physiol (Lond) 310:215-239.

Recanzone GH, Merzenich MM, Dinse HR (1992) Expansion of the cortical representation of a specific skin field in primary somatosensory cortex by intracortical microstimulation. Cereb Cortex 2:181-196.

Recanzone GH, Schreiner CE, Merzenich MM (1993) Plasticity in the frequency representation of primary auditory cortex following discrimination training in adult owl monkeys. J Neurosci 13:87-103.

Redies H, Brandner S (1991) Functional organization of the auditory thalamus in the guinea pig. Exp Brain Res 86:384-392.

Redies H, Sieben U, Creutzfeldt OD (1989) Functional subdivisions in the auditory cortex of the guinca pig. J Comp Neurol 282:473-488.

Reiter HO, Stryker MP (1988) Neural plasticity without postsynaptic action potentials: less-active inputs become dominant when kitten visual cortical cells are pharmacologically inhibited. Proc Natl Acad Sci USA 85:3623-3627.

Richardson R, DeLong M (1988) A reappraisal of the functions of the nucleus basalis of Meynert. Trends Neurosci 11:264-267.

Salzman K, Britten K, Newsome W (1990) Cortical microstimulation influences perceptual judgements of motion direction. Nature 346:174-177.

Sastry BR, Goh JW, Auyeung A (1986) Associative induction of posttetanic and long-term potentiation in CA1 neurons of rat hippocampus. Science 232:988-990.

Scheich H (1991) Auditory cortex: comparative aspects of maps and plasticity. Curr Opin Neurobiol 1:236-247.

Schlaggar BL, Fox K, O'Leary DDM (1993) Postsynaptic control of plasticity in developing somatosensory cortex. Nature 364:623-626.

Schreiner CE, Sutter ML (1992) Topography of excitatory bandwidth in cat primary auditory cortex: single-neuron versus multiple-neuron recordings. J Neurophysiol 68:1487-1502.

Sejnowski TJ, Tesauro G (1989) The Hebb rule for synaptic plasticity: algorithms and implementations. In: Neural models of plasticity (Byrne JH, Berry WO, eds), pp 94-101. San Diego: Academic.
Sherman SM, Spear PD (1982) Organization of visual pathways in normal and visually deprived cats. Physiol Rev 62:738-855.

Shulz D, Fregnac Y (1992) Cellular analogs of visual cortical epigenesis. II. Plasticity of binocular intcgration. J Ncurosci 12:1301-1318.

Sil'kis IG, Rapoport SS, Veber NV, Gushchin AM (1994) Neurobiology of the integrative activity of the brain: some properties of long-term posttetanic heterosynaptic depression in the motor cortex of the cat. Neurosci Behav Physiol 24:500-506.

Stent GS (1973) A physiological mechanism for Hebb's postulate of learning. Proc Natl Acad Sci USA 70:997-1001.

Steriade M, McCarley RW (1990) Brainstem control of wakefulness and sleep. New York: Plenum.

Steriade M, McCormick DA, Sejnowski TJ (1993) Thalamocortical oscillations in the sleeping and aroused brain. Science 262:679-685.

Stryker MP, Strickland SL (1984) Physiological segregation of ocular dominance columns depends on the pattern of afferent electrical activity. Invest Ophthalmol Vis Sci [Suppl] 25:278.

Suga N, Manabc T (1982) Neural basis of amplitude-spectrum representation in auditory cortex of the mustached bat. J Neurophysiol $47: 225-255$

Tsumoto T (1990) Long-term potentiation and depression in the cerebral neocortex. Jpn J Physiol 40:573-593.

Volgushev M, Voronin LL, Chistiakova M, Singer W (1994) Induction of LTP and LTD in visual cortex neurons by intracellular tetanization. NeuroReport 5:2069-2072.

Wallace MN, Kitzes LM, Jones EG (1991) Intrinsic inter- and intralaminar connections and their relationship to the tonotopic map in cat primary auditory cortex. Exp Brain Res 86:527-544.

Webster HH, Hanisch U-K, Dykes RW, Biesold D (1991) Basal forebrain lesions with or without reserpine injection inhibit cortical reorganization in rat hindpaw primary somatosensory cortex following sciatic nerve section. Somatosens Mot Res 8:327-346.

Weinberger NM (1993) Learning-induced changes of auditory receptive fields. Curr Opin Neurobiol 3:570--577.

Weinberger NM (1995) Dynamic regulation of receptive fields and maps in the adult sensory cortex. Annu Rev Neurosci 18:129-158.

Weinberger N, Diamond D (1987) Physiological plasticity in auditory cortex: rapid induction by learning. Prog Neurobiol 29:1-55.

Weinberger NM, Ashe J, Metherate R, Diamond D, Bakin J (1990) Retuning of auditory cortex by learning: a preliminary model of receptive field plasticity. Concepts Neurosci 1:91-132.

Wiesel TN, Hubel DH (1963) Single-cell responses in striate cortex of kittens deprived of vision in one eye. J Neurophysiol 26:1003-1017.

Wigstrom H, Gustafsson B, Huang Y, Abraham W (1986) Hippocampal long-term potentiation is induced by pairing single afferent volleys with intracellularly injected depolarizing current pulses. Acta Physiol Scand $126: 317-319$

Yoshimura Y, Tsumoto T (1994) Dependence of LTP induction on postsynaptic depolarization: a perforated patch-clamp studying visual cortical slices of young rats. J Neurophysiol 71:1638-1645.

Yoshimura Y, Tsumoto T, Nishigori A (1991) Input-specific induction of long-term depression in $\mathrm{Ca}^{2++}$-chelated visual cortex neurons. NeuroReport 2:393-396. 